\title{
Pathopsychologische Beiträge zur psychologischen Phänomenologie von Liebe und Mitfühlen.
}

\author{
Von \\ Kurt Schneider. \\ (Aus der psychiatrischen Klinik der Universität Köln \\ [Direktor: Professor Dr. G. Aschaffenburg].) \\ (Eingegangen am 10. Januar 1921.)
}

I. Gegenstand und Methode der Untersuchung.

Es könnte scheinen, als ob die Fassung des Themas zwei Pleonasmen entkjelte, aber dem ist nicht so. Es sind vielmehr darin schon zwei grundsätzliche Gesichtspunkte ausgesprochen, die den ganzen Untersuchungen vorangehen. Einmal das Bekenntnis, daß wir in der „Pathopsychologie" nicht etwa eine eigene Wissenschaft sehen, sondern nur eine psychologische Methode, so etwa, wie die experimentelle Psychologie eine solche ist, und zweitens die Einsicht, daß $\mathrm{Ph}$ äno me nologie nicht Psychologie ist, und daß wir bei phänomenologischer Untersuchung psychologischer Probleme von einer ,,psychologischen Phänomenologie" zu reden haben. Diese psychologische Phänomenologie ist empirische Wissenschaft und zu unterscheiden von der ,reinen“ Phänomenologie, der Wissenschaft vom ,Wesen“ alles dessen, was als Tatsache gegeben sein kann. Diese reine Phänomenologie bildet eine Voraussetzung aller Tatsachenwịssenschaften, also auch der Psychologie. Hjer ist etwas zu verweilen, denn eine Verwechslung war und ist häufig. Husserl $^{1}$ ) wehrt sich eindeutig gegen ein solches Mißverstehen der „Logischen Untersuchungen“. Die Phänomenologie in seinem Sinne ist keine Unterstufe empirischer Psychologie, keine ,Sphäre immanenter Deskriptionen" psychischer Erlebnisse im Rahmen der Erfahrung. ,So groß d'e methodische Bedeutung ist, welche die Phänomenologie für die Psychologie beanspruchen muß, wie wesentliche Fundamente sie auch beistellt, sie ist (schon als Jdeenwissenschaft) so

1) Ideen zur reinen Phänomenologie und phänomenologischen Philosophie. Jahrb. f. Philosophie u. phänomenol. Forschung. 1, T. T. 1913. 
wenig selbst Psychologie wie die Geometrie Naturwissenschaft". Psychologie ist eine Wissenschaft von Tatsachen und Realitäten, die Phänomene, die sie als psychologische Phänomenologie behandelt, sind reale Vorkommnisse. Die „reine“" oder ,transzendentale“ Phänomenologie aber ist Wesenswissenschaft, ,ejdetische" Wissenschaft, sie will „Wesenserkenntnisse“, keine „Tatsachen" feststellen. Sie geht zwar vom Bewußtsein, wie es sich in der psychologischen Erfahrung darbietet, a us, dringt aber von den jusychologischen zu den transzendental gereinigten $\mathrm{Pbänomenen} \mathrm{vor,} \mathrm{um} \mathrm{hier} \mathrm{das} \mathrm{ihr} \mathrm{eigentümliche} \mathrm{Gebiet} \mathrm{zu}$ erreichen. „Nicht eine Wesenslehre realer, sondern transzendental reduzierter $\mathrm{Pl}$ änomene" soll die $\mathrm{Phänomenologie} \mathrm{sein.}$

Die für die reine Phänomenologie charakteristische eidetische Reduktion kann uns hier nicht beschäftigen. Wir bleiben stehen bei der $\mathrm{Phänomenologie} \mathrm{realer} \mathrm{Erlebnisse,} \mathrm{bei} \mathrm{der} \mathrm{psychologischen} \mathrm{Phänomeno-}$ logie. Der Weg ist, wie wir sahen, ein Stück weit derselbe. Die reine Plänomenologie geht gewissermaßen durch die Psychologie hindurch, und diese Etappe verwerten wir als Psychologen und Psychopathologen. Eine solche Phänomenologie wurde zwar in der Psychiatrie immer schon getrieben, doch wurde sie als plan mäßige Forschungsrichtung erst von Jaspers ${ }^{1}$ ) eingeführt, für den das einfühlende, anschauende „Verstehen" etwas unreduzierbar Letztes ist. Aber von diesem verstehenden Erleben ist zum nach prüfbaren Wissen vorzudringen. Die einzelnen $\mathrm{Pt}$ änomene müssen begrenzt und geordnet werden, ,eine übersehbar geordnete Unendlich keit unreduzierbarer seelischer Qualitäten" ist das Ideal dieser Forschung; im Gegensatz zu der naturwissenschaftlichen Methode einer Auflösung in letzte Elemente, die nur für die Genese seelischer Qualitäten Sinn hat. Alle Theorien müssen hierbei wegfallen: „Phänomenologie kann durch Theorie nichts gewinnen, höchstens verlieren." Dieses phänomenologische Versteken, dieses anschauliche Sichvergegenwärtigen dessen, was ein anderer wirklich erlebt, heißt Jaspers ,,statisches" Verstehen im Gegensatz zu dem ,genetischen" Verstehen, dem „verstandenen Auseinanderhervorgehen".

In diesem Sinne wird vor allem unter Heranziehung guter Selbstschilderungen nun seit Jahren in der Psychopathologie gearbeitet, und in diesen Rahmen wollen sich auch die vorliegenden Untersuchungen über die erlebten Störungen der Liebe und des Mitfühlens fügen, wobei wir zunächst eine Zusammengehörigkeit dieser beiden Akte voraussetzen. Die Methode hat Grenzen und Schwierigkeiten, die zum Teil mit denen der Fremdphänomenologie überhaupt zusammenfallen, zum

1) Die phänomenologische Forschungsrichtung in der Psychopathologie. Diese Zeitschrift. 9, 391. 1912. 
Teil noch besonders durch den abnormen Seelenzustand des Untersuchten bedingt sind. Unter den ersteren sind die Grenzen der Einfühlungsmöglichkeiten zuerst zu nennen. Voraussetzung ist ferner stets eine gewisse Mitteilsamkeit, der gute Wille, das Interesse des anderen; aber gerade hierin gibt es auch ein Zuviel : es wird nicht schlicht wiedergegeben, was erlebt wird, sondern der andere erzählt unter einem sei es eigenen, sei es dem Untersucher zuliebe vorher eingenommenen, fälschenden Gesichtspunkt, ja er erlebt schon hiernach. Hier schadet Verbildung oft ebensosehr wie Unbildung. In diesem Zusammenhang schreibt $K u ̈ l \mathrm{pe}^{1}$ ) über Aufzeichnungen eines der später zu besprechenden Psychastheniker Öst er reich s: „Bei einem derselben habe ich die Vermutung nicht los werden können, daß er in die Vogtsche Gefühlslehre eingeführt worden sei und nachher auf Grund derselben seine $\mathrm{Zu}$ stände beschrieben habe." Alle diese Dinge, unter denen auch noch die Bedingung einer halbwegs plastischen Ausdrucksfähigkeit und Sprachgewandtheit zu nennen jst, gelten auch für die phänomenologische Untersuchung Abnormer; manche in verstärktem Maße. Negativistische Ablehnung, autistisches Eingesponnensein, wahnhafte Deutung der Untersuchung, erschwerte Auffassungsfähigkeit, mangelhaftes Begreifen dessen, was der Untersucher will, endlich die Unschilderbarkeit gewisser psychotischer Erlebnisse, die für den Gesunden überhaupt nicht zu vergegenwärtigen sind - etwa die ,gemachten“ Gedanken oder der „Gedankenentzug“ - das alles sind Momente, die eine planmäßige phänomenologische Untersuchung Abnormer vielfach unmöglich machen. Zu einer experimentellen Selbstbeobachtung im Sinne der Würzburger Schule sind Psychotische kaum je einmal zu bringen, aber auch das einfache planmäßige Befragen stößt allzufrüh an Grenzen. Die Technik eines solchen Vorgehens erfordert Takt und Utbung, die Verwertung der Ergebnisse vor allem Kritik. Das planmäßige Fragen darf vor allem nicht zum ,Hineinfragen" werden, andererseits aber ist ein ins einzelne gehendes Fragen doch meist ganz unentbehrlich. Man kann auch von Selbstschilderungen in der Form spontaner Briefe oder von Tagebuchblättern ausgehen, und diese sind vielleicht das objektivste Material. Dies gilt ganz besonders von Psychotischen, weit weniger von Psychopathen, unter denen namentlich der Typus der ,Selbstbespiegeler" sehr gefährlich ist. Dieses Analysieren hat Vorzüge vor dem planmäßigen Fragen: Man mag sich in der Deutung noch so weit verirren, es bleibt doch stets die Möglichkeit, zu dem grundliegenden objektiven Material zurückzukehren. Oft können solche Aufschriebe dann. sekundär zur Grundlage vorsichtigen Fragens dienen, endlich kann es auch zweckmäßig sein, das Thema anzugeben.

1) Psychologie und Medizin. Zeitschr. f. Pathopsychol. 1, 187.1912. 
Wenn wir das fließende Leben, das aus dem Erzählten und den Selbstberichten spricht, an den von der Phänomenologie herausgehobenen Begriffen zu messen suchen, werden wir oft in Schwierigkeiten kommen: hier künstlich isolierte herauspräparierte Fäden, dort ein organisches Gewebe voll konkreten Lebens. Nicht stets werden wir ein Erleben einwandfrei im Sinne der phänomenologischen Selbstbesinnung herausheben können. Meist erscheint uns alles viel komplizierter, und wir zweifeln immer wieder, ob sich das, was der andere erlebt, nun auch wirklich mit dem deckt, was unsere Begriffe meinen. Hierbei verhalten sich die einzelnen letzten Phänomene verschieden, so erscheint uns etwa die Wahrnehmung einfach gegenüber den Gefühlen. Hier zeigt es sich deutlich, wie die phänomenologische Psychologie, die reales und individuelles Leben sucht, von der eidetisch en Reduktion abbiegt. Die transzendentale Phänomenologie, aufbauend auf der Selbstbesinnung, kümmert sich nicht um diese Konkretheit realen Lebens, sie abstrahiert von Unechtheiten und Täuschungen, von Überlagerungen und Widersprüchen. So könnte der Versuch, mit phänomenologischen Begriffen an ein reales psychisches Geschehen heranzutreten, von vorn-. herein fruchtlos erscheinen. Und doch wird man, wenn man psychologisch überha u pt ordnen und zu einem Wissen gelangen will, nicht anders vorgehen können, als daß man das phänomenologisch herausgearbeitete Wesen erlebter Phänomene zur Grundlage seines Fragens und Analysierens macht.

In den vorliegenden Untersuchungen über die Störungen der Liebe und des Mitfühlens ist fast ausschließlich der Weg des Analysierens gewählt : der Leser kann selbst die Quellen zur Hand nehmen. Der Gegenstand ist noch näher zu umgrenzen. Es handelt sich nicht um Störungen der Liebe und des Mitfühlens überhaupt, sondern ausdrücklich um die als Veränderung, und zwar meist Verminderung erlebte $n$ Störungen des Mitfühlens und der Liebe. So fällt sehr viel weg: der asoziale, ethisch defekte Psychopath, der schwer Gehirnkranke, ja auch gerade die Schizophrenen, die objektiv diese Symptome am allerdeutlichsten zeigen, können nicht Gegenstand dieser Untersuchung sein. Weiter geht aus dem Ausgeführten hervor, daß wir beim statischen Verstehen bleiben, dieses selbst als eine letzte Erkenntnisquelle anerkennend, und die Theorie nur da streifen, wo sie unmittelbar an die Phänomene anschließt. Alle Erklärung des Mitfühlens ${ }^{1}$ ) und der Liebe, alle metaphysische (Schopenhauer, von Hartmann, Nietzsche), phylogenetische (Darwin, Spencer), ontogenetische (Freud), aber auch jede ethische Betrachtung (an Neueren Lipps, Störring, Scheler) berührt hier nicht.

1) Hierüber Ausführliches bei Groethysen: „Das Mitgefühl." Zeitschr. f. Psychol. u. Physiol. der Sinnesorgane. 34, 161. 1904. 


\section{Die Phänomenologie von Liebe und Mitfühlen.}

Hier sollen die Gesichtspunkte gewonnen werden, nach denen das psychopathologische Material zu betrachten ist. Die Frage ist die: Was ist überha upt Mitfühlen und Liebe als Erlebnis? Wann liegen sie vor? Welche Bedingungen haben sie? Und welche Beziehungen verbinden beide?

Die Arbeit, die uns hier am meisten interessiert und die sich am meisten zur Grundlage für psychopathologische Forschung zu eignen scheint, ist von Scheler ${ }^{1}$ ). Im Mitgefühl werden uns Erlebnisse anderer unmittelbar verständlich, außerdem nehmen wir daran teil. $\mathrm{Zu}$ scheiden ist das Mitgefühl zunächst von dem bloßen Auffassen, Verstehen, Nachleben, Nachfühlen, das Voraussetzung des Mit-, fühlens jst, aber noch zum erkennenden Verhalten gehört. Das Nachfühlen ist kein Fühlen des fremden Gefühls, sondern nur ein Urteil. Man erfaßt die in den Ausdrucksphänomenen im Sinne des Wahrnehmens unmittelbar gegebenen fremden Gefühle, ohne daß sie in einen herüberwandern. Die Nachahmungstheorie (Li p ps) macht gerade das Gegenteil echten Verstehens klar, nämlich die Ansteckung durch fremde Affekte, wobei es zunächst zu einem Mitmachen der Ausdrucksbewegungen und dann sekundär zu ähnlichen Affekten kommt. Zur Verständlichmachung des Nachfühlens ist weder „Einfühlung“ noch „Nachahmung“" nötig - diese Akte bringen gerade die Täuschungen des Verstehens hervor: die Erlebnisse werden für die eigenen gehalten.

Bei der Betrachtung des Mitgefühls sind drei Tatsachen auseinanderzuhalten: 1. Das Mitfühlen ein und desselben Leids mit jemand. Dies ist nur bei seelisch em Leid, nicht z. B. bei körperlichen Schmerzen möglich. 2. Das Mitgefühl „mit". Hier sind „mein" Leid und „sein“ Leid zwei phänomenologisch verschiedene Tatsachen, nicht eine, wie im ersten Fall. 3. Die bloße „Gefühlsansteckung“. Hier sind Nacherleben und Mitfühlen auch im Erlebnis deutlich voneinander geschieden. Beide Funktionen fallen durchaus nicht zusammen, so gehört zur Grausamkeit gerade das Verstehen. Die „Fühllosigkeit“, die mangelnde Aufnahme des fremden Erlebens, ist etwas ganz anderes als fehlendes Mitfühlen. Man kann in seine Gefühle so versenkt sein, daß es zu einer fühlenden Aufnahme des fremden Erlebens gar nicht kom $m t^{2}$ ). Bei der Gefühlsansteckung findet nun keine Gefühlsintention auf Freude oder Leid des anderen, keine Anteilnahme an seinen

1) Zur Phänomenologie und Theorie der Sympathiegefühle und von Liebe und Haß. Halle 1913.

2) Scheler versteht daraus das Gefühl der Gefühllosigkeit bei der Melancholie; wir werden später sehen, wieweit diese Deutung zutrifft.

Z. f. d. g. Neur. u. Psych. O. LXV. 
Erlebnissen, sondern lediglich eine Ansteckung zwischen Gefühls z u ständen statt, welche ein Wissen um die fremden Erlebnisse nicht voraussetzt. Es brauchen auch nicht Gefühlserlebnisse zu sein, die anstecken: auch trübes Wetter, ein tristes Zimmer können anstecken. In Massenbewegungen aller Art sieht man ein gegenseitiges, lawinenartig anwachsendes Sich-weiter-Anstecken. Der hier unwillkürlich verlaufende Prozeß kann auch gewollt werden: man sucht Zerstreuung, Aufheiterung. Darwin und Spencer, die das Mitgefühl aus den Herdensitten ableiten, verwechseln fortgesetzt Gefühlsansteckung mit echtem Mitleid. Nicht dieses ist ein "Multiplikator des Elends“" (Nietzsche), nur bei der Gefühlsansteckung entsteht im anderen ein reales Leid, ein Gefühlszustand gleicher Art wie das ansteckende Gefühl. Nicht durch das Mitleid wirkt Leiden ansteckend; gerade da, wo Leiden ansteckend wirkt, ist Mitleid ausgeschlossen, denn es ist dann nicht mehr das Leid des anderen, sondern mein Leid, das nur ka usal auf das Erleben des anderen zurückgeht. Ein Scheinmitgefühl ist auch die Uberlegung: ,Wie wäre es, wenn es mir so ginge ?" Von dieser Uberlegung ist im echten Mitgefühl nichts vorhanden, es richtet sich ja gerade auf das individuelle einzigartige Leid des anderen. Mitgefühl ist es auch nicht, wenn sich die Intention auf die eigene Reaktion auf fremdes Leid richtet: wenn jemand kein Blut sehen kann oder hilft, um einen ihn quälenden Anblick loszuwerden. Denn Mitfühlen ist niemals ein eigener intendierter Gefühlszustand, sondern nur eine Gefühlsfunktion. Der gegebene Gefühlszustand ist ganz in dem anderen. So ist echte Mitfreude: mitgenießen können, ohne daß wir selbst in eine frohe Stimmung geraten. Im echten Mitleiden oder Mitfreuen ist ein eigen er Leidens- oder Freudenzustand nicht gegeben, und so ist die Reproduktion eigenen Leides als Erklärung des Mitleids, wie sie Störring versucht, nicht zu brauchen. Reproduktion eigener Erlebnisse führt wieder zum Gegenteil echten Mitfühlens: zur Ablenkung auf sich. Da wir die fremden Gemütszustände in den Ausdrucksphänomenen direkt wahrnehmen, ist hier eine genetische Theorie überhaupt sinnlos. Mitfühlen ist ,eine letzte ursprüngliche Funktion des Geistes“, die in keiner Weise genetisch-empirisch aus anderen Vorgängen abzuleiten ist. Sie gehört, in wech selnder Stärke angeboren, zur Konstitution aller fühlenden Wesen. Die Entwicklung beim einzelnen ist zum wesentlichen Teil auf die Entwicklung des Verständ nisses fremder Erlebnisse zurückzuführen. Auch die Leidensfähigkeit spielt eine Rolle in dem Sinne, daß der Leidensfähigere und Leidende für die Schmerzen andefer mehr Verständnis hat.

Das Verhältnis von Liebe und Mitfühlen ist oft verkannt worden, namentlich von der englischen Ethik, welche die Liebe vom Mitgefühl ableitet. Liebe ist aber stets auf einen Wert bezogen und schon 
darum kein Mitfühlen. Sie ist a uch kein Fühlen und keine Funktion, sondern ein Akt. Und zwar ein spontaner Akt, nicht ein reaktiver wie das Mitfühlen, das man daher auch nur mit einem fühlenden Wesen haben kann. Allerdings ist jedes Mitfühlen in eine $m$ Lieben fundiert, aber nicht umgekehrt. Wir brauchen aber nicht den individuellen Gegenstand zu lieben, mit dem wir fühlen. Die Liebe kann auch auf ein Ganzes gehen, dessen Teil oder Beispiel der Betreffende ist. Dann aber ist Mitfühlen erniedrigend. „Das einzige, was das Mitleid erträglich macht, ist die Liebe, die es verrät." Stets ist der Akt des Mitfühlens in einen Akt der Liebe eingebettet, soll es zu mehr kommen als zu einem bloßen Nachfühlen. Es ist ausgeschlossen, da nicht mitzufühlen, wo man liebt.

Liebe aber ist überhaupt nicht auf einfachere Tatsachen zurückführbar, insbesondere nicht auf Gefühlszustände und Strebungen. Freude und Leid, die uns ein Mensch bereitet, sind unabhängig von Liebesbeziehungen. Der Akt Liebe ist auch da, wo die Liebe unglücklich ist, von Glücksgefühlen begleitet. Wohl ist die Liebe Ursache von Gefühlszuständen. F. Brenta no erkannte die elementare Aktnatur der Liebe, rechnete sie aber irrtümlicherweise zu den erkennenden Akten wie „Vorziehen". Liebe geht aber nicht auf Erkenntnis von Werten, sondern es sind die Gegenstände, welche werthaltig sind. Ein solcher beurteilender Akt wäre etwa die „Achtung“. Man kann Liebe nicht begründen; Gründe müssen erst nachträglich gesucht werden, und immer bleibt ein unbegründbares Plus. Alle Eigenschaften des geliebten Gegenstandes erhalten ihren vollen Wert erst durch den Gegenstand, der sie trägt. Sie können wegfallen, wechseln, ohne daß wir darum die Person weniger lieben; sie werden geliebt, weil sie der bestimmten individuellen Person gehören.

„Als letzte Wesenheiten von Akten sind $H a B$ und Liebe nur anschaubar zu machen, nicht definierbar." Liebe ist nicht „Reaktion" auf einen gefühlten Wert, wie z. B. ,sich freuen“, sondern Bewegung in der Richtung niederer Wert - höherer Wert. Sie geht nicht nur auf Werte an Menschen. Der höhere Wert kann, nur nicht wahrgenommen, schon existieren, oder auch nicht. Es ist, als ob er aus dem Träger selbst, ohne jede strebende Betätigung von selbst herausfließe. Echte Liebe macht sehend, nicht blind. Das Augenöffnen ist aber Folge der Liebe, nicht sie selbst ist ein Suchen nach höheren Werten, was ein Zeichen mangelnder Liebe wäre. Echte Liebe sieht die Fehler, liebt sie aber mit. Die Richtung auf das „Höhersein eines Wertes“ ist etwas anderes als die Richtung auf einen höheren Wert; hierbei bedingt schon das ,,Suchen" irgendeine Form der Erfassung des höheren Wertes seiner Qualität nach. Der ,höhere Wert" ist aber in keiner Weise vorher gegeben, sondern erschließt sich erst in der Bewegung. Liebe ist auch 
nicht Anlaß zum Schaffen höherer Werte durch Erziehung - wir lieben, den Gegenstand, wie er ist. Endlich schafft die Liebe nicht selbst die höheren Werte am anderen; das wäre Illusion, ein Nichtloskommenkönnen von der Neigung zu den eigenen Ideen. So gibt es noch viele Täuschungen: Gewohnheit, Ähnlichkeit, Interessengemeinschaft, Kameradschaft $u$. a., nach denen das Wesen der Liebe nicht beurteilt werden darf. „Liebe ist die Bewegung, in der jeder Gegenstand, der Werte trägt, zu den für ihn möglichen höchsten Werten gelangt; oder in der er sein ideales Wertwesen, das ihm eigentümlich ist, erreicht."

Entsprechend der Grundeinteilung aller Akte sind auch hier drei Formen zu unterscheiden: die geistige Liebe der Person ${ }^{1}$ ), die seelische Liebe des Ichindividuums und die vitale oder Leidenschaftsliebe. ,Sinnliche" Liebe als Artbestimmung der Liebe gibt es nicht, wenn man nicht damit sagen will, daß hier Liebe von sinnlichem Fühlen begleitet ist. Rein sinnliches Verhalten zu einem Menschen ist lieblos, denn es stellt den anderen bloß in den Dienst des eigenen Empfindens. „Es ist aber ein solches Verhalten mit jeder Art von Liebesin te n tion auf den anderen als den anderen völlig unverträglich ". Dieselbe Person kann gl eich ei tig in diesen drei Formen Gegenstand von Liebe und Haß sein, wozu noch sinnliche Neigung oder Abneigung kommen kann. Die geistige Liebe ist etwa die Liebe Buddhas oder Christi, die seelische Liebe „Freundesliebe“. ,eheliche Liebe", „Eltern"- und „Geschwisterliebe", die vitale Liebe die Leidenschaftsliebe zwischen Mann und Weib. - Bei den Arten der Liebe hat man solche zu unterscheiden, die schon als Gemütsbewegungen qualitativ, selbst, und solche, die erst durch die Richtung auf verschiedene Objektenkreise verschieden sind. Zu diesen ersten ,echten“ Liebesarten gehören Mutterliebe, Heimatsliebe, Geschlechtsliebe; sie können erlebt werden, auch wenn sie keinen Gegenstand treffen. So ist Mutterliebe nicht an Erfahrung gebunden, sie setzt das Haben von Kindern nicht voraus. Diese echten Liebesarten sind allein jenes ursprünglichen Sehnens nach Erfüllung fähig, nicht aber die Liebesarten, die sich erst durch die Objekte unterscheiden, wie etwa „Liebe zur Kunst", „Liebe zum Staat". Die Mutterliebe als zuvor schon gespürte Liebesart gehört zu den Konstitutionen des weiblichen und hat keine Analogie im männlichen Bewußtsein. - Von diesen Arten sind endlich die Modi der Liebe zu unterscheiden, ,die sich in bloßen Verbindungen von Liebesarten mit sozialen Verhaltungsweisen und Mitgefühlserlebnissen darstellen", wie „Güte“, „Neigung“", ,Zärtlichkeit", ,Anhänglichkeit“, ,Dankbarkeit“, „Pietät". Diese Modi sind wieder zu trennen von bloßen Verbindungen von Gemütsbewegungen, in denen die Liebe nur einen Bestand-

1) Eine Erläuterung des Begriffs der "Person" würde hier zu weit führen und für unser Ziel belanglos sein. 
teil darstellt, ohne dem Ganzen seinen Grundcharakter zu geben, wie „Treue", „Demut". -

Von besonderem Interesse sind ferner für uns die Ausführungen Pfänders's) über die ,u nechten" Gefühle. Es handelt sich hierbei um eigentümlich hohle, kernlose Gebilde, die den entsprechenden echten Gesinnungen als blasse Abbilder oder schemenhafte Nachahmungen genau entsprechen. Es liegen ihnen reale, zentrifugale Gefühlsstörungen zugrunde, sie sind erlebt, nicht vorgestellt, sind nicht schwache, weniger intensive Regungen echter Gefül le, sondern bilden, nach Wesen, Struktur und Formen mit den echten Gefühlen übereinstimmend, eine eigene Reihe. Mit Täuschung und Lüge haben diese unechten Gefühle nichts zu tun. Sie können echte Gefühle überdecken, auch als Lückenbüßer für sie eintreten. Auch gegenüber jemandem, den man liebt, verspürt man nicht immer aktuelle Liebe. Man kann dann die Pausen der echten Liebe mit einer blassen Nachahmung ausfüllen; auch dies ist keine Täuschung. „Es ist zu bezweifeln, ob es die geforderten lückenlosen echten positiven Gesinnungen in dem Seelenleben irgendeines Menschen wirklich gibt." Echte und unechte Gefühle können sich auch in einer Gesinnung vereingen. Vor allem können echte Gesinnungsregungen mit unecht gesteigerter Intensität vorkommen. Auch kann eine echte geradausblickende Liebe zu einer unecht hinaufblickenden umgeformt werden und umgekehrt. Aus der Entdeckung unechter Momente in bestehenden Gesinnungsregungen darf man nicht ohne weiteres auf die Unechtheit der ganzen Gesinnungsregung schließen. Die unechten Momente können bemerkt werden. Manche Menschen leiden an jeder unechten Gesinnungsregung ganz unberechtigt mit bösem Gewissen. Unechte Gesinnungen können auch echten den Weg bereiten. Das unecht Psychische gibt es überall: bei Lust, Freude, Unlust, Trauer, Heiterkeit, Genießen, auch auf dem Gebiete des Strebens und Wollens, des intellektuellen Lebens, des Glaubens, des Sich-Erinnerns, des Aufmerkens und Nachdenkens. Das Unechte ist ,eine einzigartige, durch das ganze aktuelle seelische Leben ausgebreitete Spl. äre". -

Zur. Plänomenologie der Liebe und insbesondere ihrer Beziehung zum Versteken und Mitfüllen hat auch Jaspers ${ }^{2}$ ) sich geäußert. 'Teilweise decken sich seine Ansich ten mit denen Schelers. Die Liebe hat mit den Trieben gemeinsam die Bewegung, ,,aber sie ist allen Trieben entgegengesetzt, insofern sie allein über das Individuum erlebnismäßig

1) Zur Psychologie der Gesinnungen. Jahrb. f. Philosophie u. phänomenolog. Forschung. 1, T. I. 1913. - Vergl. auch Haas, Über Echtheit und Unechtheit von Gefühlen. Dissertation. München 1910 und Zeitschr. f. Pathophsychol. 2. 1914.

2) Psychologie der Weltanschauungen. Berlin 1919. 
hinausgeht". In der Bewegung der Liebe wird alles wertvoller; es wird ein Prozeß der Werterhöhung erlebt. „Zwischen Menschen ist Liebe zugleich das, was das vollkommene Verstehen heißt." Dieses liebende Verstehen darf nicht mit dem psychologischen Verstehen verwechselt werden. Auch das gesteigerte psychologische Verstehen ist kein liebendes Verstehen, doch setzen Liebe (und Haß) das psychologische Verstehen in Bewegung. „Psychologisches Verstehen ohne Liebe und Haß kommt nicht weit, kann nur reproduzieren, nicht neu sehen." Mitleid ist nicht Liebe, aber ebenso wie psychologisches Verstehen eine Manifestation des liebenden Verstehens. Während die Liebe den Menschen absolut und eingebettet in das Absolute nimmt, hat Mitleid nirgends Beziehung zum Absoluten, ist bloß leidverneinend, gar nicht auf das Individuum gerichtet - darum entwürdigend für den Betroffenen. Es ist der äußerste Gegensatz von Liebe, in Mitleid sich auszusch ̈̈tten. Immer meint man dabei sich selbst; man bleibt in der Einstellung, der der Wertgegensatz Leid und Lust der absolute ist. "Man liebt nicht, wenn und weil man mitleidig ist." Es ist auch nicht Liebe, wenn man durch Erzieh ung den Wert hinauf. steigert. Auch hineinsehen kann man alles Wertvolle in einen Menschen. Auch diese illusionäre Umkleidung ist ein Feind der Liebe. Die Liebe ist hellsichtig, nicht blind. „Man liebt den Menschen mit seinen Fehlern, in seiner Wirklichkeit, die im Absoluten liegend gesehen und als Prozeß im Kampfe liebenden Verstehens erfahren wird." Man liebt kein ruhendes Etwas. Das fertige, bewegungslose Verstehen ist kein liebendes Verstehen. - In der Liebe gibt es einen polaren Gegensatz der Arten: „,Der eine liebt aus der Welt hina us und vergißt die Welt, die Realität; der andere liebt in der Welt und vergißt das Absolute." Der erste (seinem Typus entspricht Franz von Assisi) liebt. entsprechend der platonischen Eroslehre, nicht Individuen, sondern die Ideen, der andere, entsprechend der modernen Formel, das Individuum als Individuum. Die echte Liebe besteht aus der Synthese dieser Gegensätze. Dem ersten Typ kommt es auf Handeln und Folgen in diesėr Welt nicht an, dem zweiten sind sie wichtig. Auch der nicht alles, sondern ein Individuum Liebende läßt seine Liebe über alles ausströmen, doch bleibt hier im Zentrum die Liebe zum konkreten Individuum. Die des Zentrums entbehrende, wahllose Liebe führt zur Auflösung. Sie tendiert zur mystischen Liebe, zur ruhenden Vereinigung, zum infolge Aufhebung der Subjekt-Objektspaltung gegenstandslosen Liebesgefühl. Bemächtigt sich die an sich universale Liebe der Erotik, die in der Krystallisation aller Werte um das Geliebte etwas der Liebe Verwandtes hat, aber polygam ist, erfährt sie ,,jene absolut individuelle und einmalige Fixierung, die unwiederholbar ist." Bei aller Ausschließlichkeit fühlt der Liebende überall seine Liebe wachsen, worin sich 
eben zeigt, daß es Liebe ist. Die Liebe bemächtigt sich auch der rein vitalen Sexualität. „Es ist ein Kampf zwischen diesen Sphären, wobei Sexualität und Erotik untereinander wohl oft, alle drei zusammen wohl nur in seltenen Glücksfällen eine lebendige Synthese eingehen." So kann man in der Beziehung der Geschlechter Sexualität, Erotik und „metaphysische" Liebe unterscheiden.

Diese eingehende Heranziehung phänomenologischer Ergebnisse war notwendig, selbst wenn wir bei der Untersuchung realer psychologischer Tatbestände nicht stets mit ihnen allen arbeiten können. Besonders wichtige und für die Psychopathologie der in Frage stehenden Phänomene brauchbare Gesichtspunkte, die wir gewannen, sind folgende:

1. Die Liebe ist eine letzte, nicht weiter zurückführbare Wesenheit von Akt.

2. Es gibt verschiedene, phänomenologisch zweifellos geschiedene Arten von Liebe, wie Gattenliebe, Geschwisterliebe, Freundesliebe.

3. Es gibt verschiedene Modi, Verbindungen von Liebesarten mit sozialen Verhaltungsweisen und Weisen des Mitgefühls, wie „Güte“, „,Neigung“", „Zärtlichkeit“, „Anhänglichkeit“, „Pietät“.

4. Das Mitgefühl ist eine letzte, ursprüngliche Funktion, aber im Lieben fundiert. Einerlei, wie die Beziehungen im einzelnen gefaßt werden (vgl. Jaspers und Scheler): es ist unmöglich, da nicht mitzufühlen, wo man liebt. Und so wird das Dasein oder Fehlen des Mitfühlens stets - namentlich den Erlebenden selbst a uf das Dasein oder Fehlen von Liebe schließen lassen.

5. Verstehen, Nachfühlen ist eine Bedingung des Mitfühlens, aber nicht dieses selbst.

6. Dieses Verstehen wird seinerseits wieder verfeinert durch größere Leidensfänigkeit und größeres eigenes Leiden.

7. Vom Mitfühlen ist die Gefühlsansteckung zu trennen, die gerade nicht auf das fremde Leid geht.

8. Neben dem echten Psychischen läuft als genaue Nachahmung eine Reihe des unecht Psychischen. Es gibt auch unechtes Mitfühlen und unechte Liebe, die nicht etwa Unaufrichtigkeiten sind.

\section{Die subjektive Psychopathologie von Liebe und Mitfühlen.}

A. Klagen von Kranken, daß sie keine Liebe und kein Mitfühlen mehr empfänden, werden in der Psychiatrie, besonders bei Gelegenheit der subjektiven Gefühlshemmungen, des Gefühls der Gefühllosigkeit Melancholischer, häufig erwähnt,.sind aber, soweit ich sehe, nie zum Gegenstand besonderer Untersuchung gemacht worden. Material zu solchen Untersuchungen findet sich an folgenden Orten: 
Förste ${ }^{1}$ ) beschrieb eine 49 jährige Frau, die seit Jahren an Entfremdung ihrer Wahrnehmungen und Vorstellungen litt, auch ihren eigenen Körper nicht mehr empfand. Ferner klagte sie, Kinder und Mann seien ihr gleichgültig, sie habe keine Liebe mehr zu ihnen.

Oesterreichs ${ }^{2}$ ) depersonalisierter Kranker Ka., der sich aufs sorgfältigste beobachtete, äußerte: „Keine Vorstell ung, a uch nicht die der mir liebsten Personen, vermochte irgendein Gefühl in mir zu erwecken." Weiter: „Ein sehr feines Reagens für meinen Zustand ist das Folgende: Photographien mir bekannter Personen haben etwas Fremdes im Ausdruck. Hier konnte ich besonders deutlich konstatieren, daß die Gefühlstöne, die die Photographien sonst hervorrufen, verdumpft, nicht hell waren : sie klangen nicht hell, sondern blieben dumpf. Namentlich die positiven Gefühle, aber auch die negativen." Sein zweiter Kranker, der 20 jährige Ti., klagt, Vater und Mutter seien wie alles andere „ohne jeden Gefühlston": „Ich habe nicht meine frühere Gefühlsbetonung. Ich weiß, daß ich im Grunde ein guter Sohn bin und mir der Tod meiner Mutter das Schrecklichste ist, was mir passieren könnte. Und doch kann ich mir jetzt ihren Tod und den meines Bruders ohne alle Gemütsbewegungen ausmalen." Nach der Liebe zu seiner Mutter gefragt, sagt er: „Ich liebe meine Mutter, aber ich habe keine Empfindung. Es ist, als ob ich das Wort ausspreche, ohne zu empfinden, was ich spreche." Auch beim Tode des Vaters habe er keine Trauer gespürt. Auch die Verwandten berichteten, er habe keine Gefühle mehr für sie, kränke seine Mutter absichtlich, ohne Mitleid zu haben. Der dritte Kranke, der 35jährige Philologe Prau, klagte: „Meine natürliche Sensibilität macht mich leider sehr geeignet, fremdes Leid mitzufühlen; dazu kommt zu meinem Unglück ein unausrottbarer Trieb, zu helfen, wo ich kann; wenn sich immer wieder Menschen mit einem mir unbegreiflichen Vertrauen an mich wenden, so lasse ich sie nicht gern im Stich. Aber freilich bin ich dadurch gemütlich öfter und mehr engagiert, als es nötig wäre. Wäre ich gesund, so würde ich, wie ich glaube, helfen können, ohne mit zu leiden." Auch Kranke Krishabers und Leroys, die Oesterreich zitiert, sagen Ähnliches aus.

Schilders ${ }^{3}$ ) 21 jähriger depersonalisierter schizophrener Student M. klagt. sein Charakter sei verändert: „Weil ich niemanden mehr liebhabe; Seele habe ich gar nicht mehr." Er sagt weinend zum Arzt: "Ich möchte mit Ihnen lieb sein, aber ich kann das nicht mehr." An seine Angehörigen schreibt er zärtliche Briefe, klagt aber: „Ich kann den Eltern nichts Liebes mehr erweisen." Eine 27jährige, wahrscheinlich psychasthenische Arzttochter beginnt ihre Selbstschilderung: „Vor allen Dingen will ich betonen, daß mir von Natur aus das Gefühl der Liebe, zu wem es auch sei, zu Angehörigen, nicht mit a uf die Welt gegeben worden ist. Ich wußte immer bloß, daß ich zu den Meinigen gehöre. Sogar die vielgepriesene Mutterliebe ging mir ab - Kinder waren bei mir nur ein Spielzeug -, aber nicht, weil ich so schlecht war, sondern weil es mir eben nicht gegeben war, zu ermessen und zu erfassen, was ein Kind heißt. Ich hörte bloß immer von anderen: ,das Kind, das Kind', ich selbst hatte kein Vesrtändnis dafür. Mir konnten Menschen höchstens sympathisch sein, aber deswegen suchte ich die auch nicht öfters auf,

1) Ein Fall von elementarer allgemeiner Somatopsychose. Monatsschr. f. Psych. 14. 1903.

2) Die Entfremdung der Wahrnehmungswelt und die Depersonalisation in der Psychasthenie. Journ. f. Psychol. u. Neurol. 7. 1905. 8. 1906. 9. 1907.

3) Selbstbewußtsein und Persönlichkeitsbewußtsein. Berlin 1914. 
als die anderen." Sie macht sich Vorwürfe, sie könne ihren Angehörigen ihre Liebe nicht vergelten. Diese selbst halten sie tatsächlich für gefühlskalt. Eine melancholische Kranke Schilders sagt, die Angehörigen sollten nicht kommen, sie könne nichts für sie empfinden, könne nicht freundlich sein ,wie ein Mensch".

Auch Försterlings ${ }^{1}$ ) wohl sicher schizophrene Patientin, das 26 jährige Fräulein K., schildert in ihrer "Lebensgeschichte einer toten Seele" Ähnliches: „Ich fühlte und empfand nichts mehr, keine Liebe, keine Wärme.“

B. Die nun folgenden eigenen Beobachtungen über die erlebten Störungen der Liebe und des Mitfühlens ordnen wir nach den psycho. logischen, aus der Phänomenologie dieser Phänomene abgeleiteten Formen. Wir machen noch folgende Einschränkung: es handelt sich nicht um die begründete oder unbegründete Verminderung der Liebe zu einer bestimmten Person, dies ist nur in einer Beobachtung zu sehen, sondern um die ganz allgemeine Klage, daß Liebe und Mitfühlen überhaupt vermindert oder erloschen seien. Die Störung betrifft alle Liebesarten, Gattenliebe, Kindesliebe, Geschwisterliebe, Freundesliebe, Nächstenliebe. Es wird der empirischen Betrachtungsweise selten möglich sein, nachzuweisen, ob und wieweit solche Liebe mit „Anhänglickkeit", „Pietät" und anderen Verhaltungsweisen gemischt ist, auch nicht, ob und wieweit unechte Züge mitspielen. Die im Sinne von Scheler und Jaspers ganz, ,reine“ Liebe, die allen pl.änomenologischen Kriterien des Wesens der Liebe genügt, dürfte zum mindesten für die objektive Beobachtung kaum einmal sicher nachzuweisen sein. Ja streng geseh en würden wir wohl oft sagen müssen, daß es sich um die ,billige Gemütsbewegung passiver und folgenloser Art" handelt, die sich wohl fälschlich Liebe nennt (Jaspers). Die Realität des konkreten Lebens kennt keine reinen Wesenheiten, sondern zeigt fast stets unreine Formen.

Wir trennen die Störungen des Mitfühlens nicht von denen der Liebe, weil wir ihre Beziehungen kennen. Am fehlenden Mitfühlen wird von a uBen und innen zumeist die fehlende ljiebe erkannt. Durchaus nicht stets brauchen Störungen des Mitleidens solche der Mitfreude parallel zu gehen; über die sich hier ergebenden Möglichkeiten wird anläßlich der letzten Beobachtung gesprochen werden. Dies wird auch die einzige Gelegenheit sein, bei der vom Erleben der Steigerung von einzelnen Phänomenen zu reden ist.

a) Die Anlage, mitzufühlen und zu lieben, darf wohl als allgemein angesehen werden, doch gibt es hiel zweifellos Grade. Auch der einzelne bleibt sich hierin nicht stets gleich, er kann sich in den verschiedenen

1) Persönlichkeitsbewußtsein und Organgefühle. Monatsschr. f. Psychiatrie. 34. 1913. 
Altersepochen verschieden verhalten, $\mathrm{ja}$ an einzelnen Tagen anders reagieren als an anderen. Was das Mitgefühl anlangt, so sind hier die Selbsterfahrungen im Felde ein evidenter Beweis. Allerdings zeigen gerade sie, wie häufig die Gefühlsansteckung und andere Täuschungen das echte Mitfühlen überlagern.

Wir besprechen zuerst die Formen, in denen Liebe und Mitfühlen tatsächlich in geringem Maße vorhanden sind, und der Träger sich dieser Figenschatt bewußt wird.

a) Es kann sein, daß einem seiner Konstitution nach ,kalten“ Menschen an irgendeinem Punkte seines Lebens diese Defekte erschreckend deutlich werden. Das wird besonders bei Gelegenheit von irgendwelchen starken Erlebnissen sein, die eine Selbstzerpflückung zur Folge haben. Dann besteht, wie bei jener Arzttochter Schilders, stets die Gefahr, daß die Selbstkritik über das Ziel hinausgeht, daß auch echtes Lieben und Mitfühlen als unecht oder untief verurteilt wird. Es scheint geradezu ein Gesetz zu sein, daß diese Akte nur in einem gewissen Halbdunkel gedeihen, und daß sie unter der vollen selbstbeobachtenden Zuwendung zu zerfließen drohen. Wenn man sich bei jeder Regung der Liebe und des M:tfühlens fragt: ,ist das echt?", wird man meist geneigt sein, an der Echtheit zu zweifeln. Ob man hier unecht Psychisches im Sinne von Pfänder und Haas oder eben nur eine Verminderung, ein Kleinerwerden der Erlebnisse annehmen muß, wird der nach Realitäten fragende Psychologe kaum einmal entscheiden können.

Diese Dinge seien durch eine Beobachtung erläutert, in der wir sehen, wie ein verwöhntes junges Mädchen, das zweifellos und auch nach objektivem Bericht die Fähigkeiten der Liebe und des Mitfühlens in wenig reichlichem Maße besitzt, bei Gelegenheit einer nicht zustande gekommenen Verlobung sich dieses Mangels bewußt wird, in der Stimmung der Selbstzergliederung aber sichtlich übertreibt.

Beobachtung 1. Die 24jährige Anne-Marie Rost ${ }^{1}$ ), ein ungewöhnlich hübsches und elegantes Mädchen aus sehr wohlhabender Familie und aus großen Verhältnissen, wurde in die Klinik gebracht, weil sie anschließend an eine mißglückte Verlobung unstillbare Verzweiflungsausbrüche gezeigt, dauernd geweint und auch vom Sterbenwollen gesprochen hatte. Sie erschien innerlich sehr erregt, bestritt, daß ihr etwas fehle, meinte, sie sei nur ein schlechter Charakter, und erzählte unter lebhaften Selbstanklagen ihre Geschichte. Sie habe immer nur die erste Rolle in der Gesellschaft gespielt, habe das Leben „,viel zu leicht" genommen und sich auch mit ernster Lektüre nicht aus Bedürfnis beschäftigt, sondern weil sie geglaubt habe, ,der Mensch muß tiefere Interessen haben". Mit etwa 19 Jahren habe sie sich mit einem ihr eigentlich nur oberflächlich bekannten

1) Sämtliche Namen sind Decknamen. Bei der Mitteilung der Fälle ist nur das hier Interessierende ausgeführt, im übrigen soll nur in groben Strichen die psychologische und psychiatrische Gesamtsituation skizziert werden. 
frischen jungen Leutnant verlobt aus dem Gefühl heraus, „mit 19 Jahren muß man verlobt sein". Nach zwei Tagen sei er ins Feld abgereist. Sie sei zunächst glücklich gewesen, aber mehr über den Zustand, verlobt zu sein. Als der Bräutigam nach einigen Monaten wiedergekommen sei, habe sie sich immer fragen müssen: "Ist das Glück?" Sie habe dann gleich sich sehr angestellt, geheult und nicht ein noch aus gewußt. Wochenlang sei sie im Zweifel gewesen, was sie tun solle, schließlich habe sie die Verlobung gelöst. Sie sei sehr erleichtert und gleich wieder ganz die Frühere gewesen und habe wieder ,mit Tausenden geflirtet". Vor etwa 2 Jahren habe sie einen nicht mehr ganz jungen, ernsten Herrn kennengelernt, an dem sie sehr hinaufgesehen habe, ohne ihn aber eigentlich lieben zu können. Sie hätten korrespondiert und sich gelegentlich gesehen, wobei sie dann stets von ihm ,,begeistert" gewesen sei und oft gedacht habe, ,wenn du dir den nicht festhältst...". Dazwischen sei sie aber auch immer mit ihren anderen Freunden zusammen gewesen, und es seien ihr immer wieder Zweifel gekommen, namentlich als ein Jugendbekannter sie lebhaft umworben habe. Bei einer Zusammenkunft habe sie dann dem anderen ihre Zweifel und Unschlüssigkeit erzählt, worauf er ihr gründlich die Meinung gesagt habe über ihren Mangel an Ernst und ihre grenzenlose Verwöhntheit. Sie solle zunächst einmal etwas Tüchtiges arbeiten, dann könne man wieder reden. In großer Aufregung sei sie vor 8 Tagen von diesem Zusammensein nach Hause gekommen und seitdem in heller Verzweiflung. Sie werde überhaupt nie fähig sein, einen Mann wirklich zu lieben, es werde bei ihr immer wieder so gehen. Sie habe seitdem keinen anderen Gedanken, zu nichts Lust und Angst vor allen Leuten zu Hause, denn sie glaube, es habe sich schon wieder herumgesprochen, wie es ihr wieder ergangen sei. Sie sei überhaupt ein übler Charakter, habe sich nur immer verwöhnen lassen, sei auch ihren Eltern nicht richtig dankbar gewesen. Das Leben habe für sie keinen Zweck mehr, da sie doch nie die Energie zu einer dauernden Neigung aufbringen könne. Dabei müsse sie unbedingt heiraten; ledig zu bleiben sei ihr der entsetzlichste Gedanke.

Dieser Zustand der Verzweiflung danerte wochenlang an, allerdings mit Unterbrechungen. Mitunter gelang es dem psychotherapeutischen Bemühen, für das sie sehr empfänglich war, ihr wieder Halt zu geben, doch immer wieder kamen elementare Schmerzausbrüche und Zustände völligen Aufgelöstseins. Sie erging sich täglich in wilden Selbstanklagen; alle möglichen Erlebnisse brachte sie vor. Die Klagen, innerlich leer zu sein, nicht dauernd lieben zu können, kehrten immer wieder. Aus Briefen, die sie in ihren Stimmungen in großer Zahl schrieb, sind folgende Stellen bemerkenswert: ,Wenn es mir schlecht ging, hatte und habe ich stets das allergrößte Mitleid mit mir selber, das Weh von anderen fühlte ich immer $n$ ur in kleinstem Maßstabe mit. Daß es mir in der letzten Zeit ganz besonders gut ging, daß ich überall die erste Rolle spielte, war selbstverständlich für mich, daß es anderen nicht so gut ging, genau die gleiche Selbstverständlichkeit. Je tiefer ich in mich hineinsehe, desto größeres Grauen empfinde ich und immer weniger Mut und Selbstvertrauen, das ändern zu können, weil es vielleicht nicht so sehr an der Oberflächlichkeit wie an Gefühlsmangel liegt." — ,. . daß ich ganz bestimmt anders fühle wie andere, kälter und weniger intensiv und nicht begeisterungsfähig und nicht konstant." - „Ich werde immer mehr jedes Gefühlchen, wenn überhaupt eins da ist, zerpflücken und zergliedern." - ,Wie glücklich die Menschen, bei denen jedes Gefühl echt ist oder die nicht darüber grübeln, ob vielleicht ein anderes noch dahinter steckt. Habe ich meine Eltern solieb, wie ich müßte? Nein. Dieses Gefühl muß doch immer da sein, tief und fest, wie Kindesliebe zu den Eltern, die einem alles und alles zuliebe tun. Es 
reicht zu Gefühlchen, kleinen, erbärmlichen, und nichts Großes ist da. Würden Sie unter dieser Erkenntnis weiterleben können ? Ich glaube es nicht. Eine große Echtheit $m$ u in jedem Leben sein, das wert ist, gelebt zu sein. Dankbar muß man sein können für das Schöne, das es auf der Erde gibt،“ - „Keine Gefühle, daß ich anderen oft furchtbar weh tat, über alles hinweg!"

Tageweise schien sie wieder Boden unter den Füßen zu haben, doch wurde sie naeh einem Monat entlassen, ohne daß sehr viel erreicht zu sein schien. Briefe aus der Sommerfrische zeigen meist diese alte Stimmung:

,Wenn ich mich jetzt frage: bin ich Ihnen wirklich dankbar, dann muß ich auch das verneinen. Herr Doktor, das kann doch nicht sein! Ein ausgebrannter Krater und dazu vielleicht noch ein langes Leben. Ich jage hinter Gefühlen her und nichts, nichts ist da.“ — ,Kann es nicht damit zusammenhängen, daß ich die Menschen mir nicht mehr vorstellen kann? Wenn sie fort sind, daß ich nur noch ihr Wesen und Denken kenne, aber alle Äußerlichkeiten fehlen? Nein, das glaube ich nicht, aber mit der Empfindungslosigkeit muß es zusammenhängen; wenn ein Gefühl nicht bis auf den Grund dringen kann, weil kein Grund vorhanden ist, dann kann es ja keine Lebensfähigkeit haben.“ - „Warum kann ich ein paar Stunden lang ganz wahr und echt für irgend jemand empfinden und dann ein plötzlicher Wechsel und ich laufe in Unruhe umher, weil mir der Wechsel so unerklärlich ist." — ,Wehe, wenn man fühlen muß, daß alle Schönheiten, ganz gleich, welche es sind, keinen Widerhall in der eigenen Seele erwecken können; es kommt ja nicht auf die Dinge an sich an, sondern immer nur auf das Echo in uns selbst.“ - „Ein weibliches Wesen ohne Herz und ohne den Intellekt, das vergessen zu können, können Siesichetwas Furchtbareres denken?" - „Man kann sich doch nicht zum Fühlen erziehen." — „Ich erlebte traurige Schicksale bei anderen Menschen, nicht das leiseste MitgefühI regte sich. Der Krieg ging vorüber und machte mich nur ganz zeitweise traurig. Jedenfalls habe ich die Größe, die in diesem Welterleben stand nicht erfaßt". - "Von allen Seiten wird mir so viel Liebe entgegengebracht und desto mehr empfinde ich, wie fremd ich meinen Angehörigen gegenüberstehe als wenn ich so gar nicht zu ihnen gehörte." _ ,Wo ist Dankbarkeit und wo ist die warme Liebe $z u$ meinen treuesten Eltern geblieben?" -

Etwa einen Monat nach der Entlassung trat dann ziemlich plötzlich, als das gefürchtete Wiedersehen mit der Heimat wider Erwarten günstig ausfiel, eine Wendung ein. Fräulein Rost trat als Schülerin in eine Gartenbauschule ein und arbeitet dort schon ein Jahr mit Eifer und Freude, ohne daß die alten Zustände sich wiederholten. Die Verlobung ist bisher nicht zustande gekommen.

Es sei noch erwähnt, daß eine kluge und objektive Verwandte bestätigte, daß Fräulein Rost stets unbändig nach allen Seiten geflirtet habe, auch habe sie stets einen grenzenlosen Egoismus gezeigt und immer nur an sich gedacht. Zwei Geschwister des Vaters, ein Bruder und eine Schwester, blieben nach endlosen Liebes- und Verlobungsgeschichten ledig, weil sie sich nie entschließen konnten.

ß) Der Mangel an Fähigkeit, zu lieben, mitzufüblen, kann aber auch geworden sein. Dies kann entwicklungs mäßig geschehen sein: ein Mensch erlebt, etwa mit dem Altern, eine zunehmende Erkaltung in seinen Beziehungen zu den Menschen. Dies ist das Erlebnis Werfels in dem Gedicht „Das erkaltende Herz" mit dem Beginn: „Geschwisterliebe war einst." und dem Schluß: 


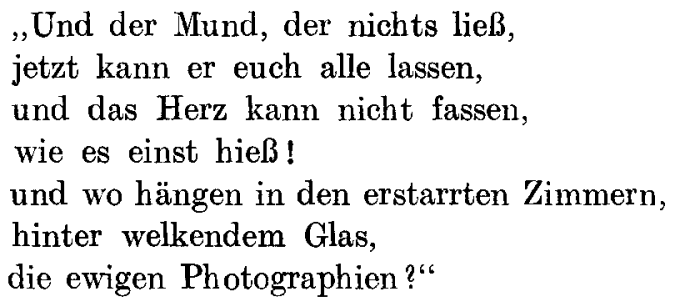

$\gamma$ ) Dieses kann auch prozeßmäßig erfolgen. In Prozessen, die eine Persönlichkeit zerstören, leidet auch Liebe und Mitfühlen oder geht zugrunde ${ }^{1}$ ). Uns kommt es hier nur auf die Beobachtungen an, in denen dies erlebt wird. Ein solches Erlebnis ist bei groben Gehirnprozessen, etwa der Paralyse, denkbar, doch habe ich nie etwas Derartiges gesehen. Die rasch zerfallende Intelligenz, die Urteilsschwäche und auch die Gedächtnisschwäche dürften daran schuld sein. An psychischen Prozessen Leidende, die dem Betrachter evident ein Nachlassen des Interesses und der Teilnahme auch an den nächsten Menschen zeigen - auch bei ,geheilten" Schizophrenen empfinden die Angehörigen diese Trennung meist sehr deutlich ... erleben diese Veränderung nicht gerade häufig, aber doch gelegentlich. Hierher gehört vielleicht Schilders Student, vielleicht auch Försterlings schizophrene Patientin. Da bei Schizophrenen aber auch mitunter Gefühlsentfremdungen vorkommen, ist es nicht ganz sicher, ob nicht diese vorliegen.

Beobachtungen, in denen es sich sicher um das erlebte Nachlassen der Liebe und des Mitfühlens handelt, sind folgende:

Beobachtung 2. Die Krankheit der zur Zeit der Beobachtung 30 jährigen Kaufmannsfrau Martha Herz reichte nachweisbar bis in ihr 20. Jahr zurück. Sie kam damals zum Hausarzt wegen Atembeschwerden und fragte ihn nachher, warum er sie bei der ersten Untersuchung hypnotisiert habe. Sie begann bald ihre Umgebung zu verdächtigen, das Kindermädchen mache unsittliche Dinge mit den Kindern, der Arzt habe gesagt, ihre Kinder hätten ,Hallunkengesichter": sie sprach von Verfolgern, gegen die sie sich noch mit der Pistole wehren müsse,

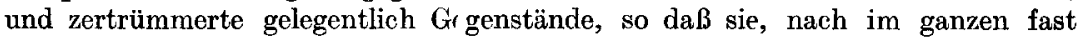
einjähriger Krankheitsdauer, in eine Privatanstalt gebracht werden mußte. Dort zeigte sie massenhaft Verfolgungsideen: sie hörte schimpfen, roch ekelhafte Gerüche, glaubte, nachts vergewaltigt worden zu sein, verbaute deshalb die Türe. Sie war zeitweise ablehnend, zeitweise wieder ganz gesellsohaftsfähig, dann wieder wehrte sie sich in höchster Erregung gegen ihre vermeintlichen Verfolger. Nach einem halben Jahr kam sie von da in die Klinik. Sie schien äußerlich ganz geordnet und benahm sich völlig korrekt, doch brachte sie, danach gefragt, ganz phantastische Dinge vor: sie werde durch Fernhypnose behandelt, in jener Privatanstalt sei sie einmal in eine Kammer gebracht worden, in der lauter Skelette

1) Uns interessiert hier nur die empirische Seite, nicht die mögliche metaphysische Gegensetzung von "Geist" und „,realer Entfaltung“. - 
gewesen seien, sie höre dauernd Silben und Worte, deren Sinn sie nicht verstehe. Oft beschwerte sie sich, nachts ,im Morphiumschlaf" gelegen zu haben, dann wieder, sie könne vor lauter Lärm keine Ruhe finden, farbige Kugeln liefen an der Deoke hin und her, manchmal sei es ihr auch, als sehe sie Gesichter. Einmal frug sie die Pflegerin, ob sie hier wirklich in einem Bordell sei. Sie klagte über ein seltsames Gefühl der Verdorrtheit im Halse, ihre Augen würden kleiner und seien bald nicht mehr da. Mitunter war sie sehr erregt, so warf sie dem Arzt vor, daß er sie ,,in Gestalt des Oberleutnants v. S.“ nachts miBbrauche, ihr „durch Vibration" seine Liebe sage, aber meist blieb sie äußerlich vollkommen geordnet. Außerhalb der mit den Sinnestäuschungen zusammenhängenden Erregungen war sie recht gleichgültig. Einmal äußerte sie darüber: „Ach diese Abstumpfung jeglichen Gefühls. Ich muß mir ordentlich Mühe geben, überhaupt etwas zu wünschen. Das ist doch zum Beispiel unnatürlich: ich denkeja wohl manchmal an meine Kinder - aberdaßauch die Mutterliebe so abstumpfen kann!"

Beobachtung 3. Die eben 18 jährige Leonie Kahn, Kind sehr reicher und äußerst besorgter Eltern, fiel mit etwa 17 Jahren auf einer Schweizer Reise zum erstenmal auf durch eine Veränderung ihres Wesens. Sie tat bei einem Tanzkurs in einem Hotel im Engadin, ohne daß sich irgend etwas ereignet hatte, plötzlich nicht mehr mit, fand alles ekelhaft, wurde menschenscheu, fühlte sich durch ihı Judentum bedrückt. Dies gab sich wieder, und sie kam in ein deutsches Pensionat, wo sie aber keinen rechten Anschluß fand, was zum Teil in antisemitischer Stimmung real begründet war. In den ersten Wochen ihres dortigen Aufenthaltes schrieb sie in ihr sorgfältig geheimgehaltenes Tagebuch folgende Verse, die zeigen, daß sie eine Veränderung ihrer Persönlichkeit erlebte:

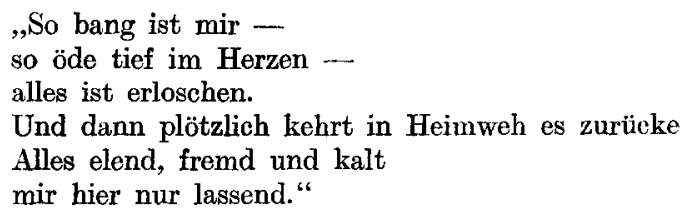

In den Weihnachtsferien, wenige Wochen nachher, war sie zuerst übermäßig lebhaft, dann ungewöhnlich ,patzig", unlenksam und ungezogen. Sie kritisierte an den Eltern herum, freute sich an nichts und ging nicht in Gesellschaft. Damals schrieb sie folgende Verse:
„Und wieder sitz ich unter dem Baum, und wieder träum ich den alten Traum, nur müder scheint er als sonst zu sein, und wieder hüllt mich das Duften ein, und wieder umgibt mich der milde Glanz, nur fehlt mir der Frohsinn heute ganz. Und ich weiß, wenn die Kerzen abgebrannt, verlier ich das letzte vom Kinderland."

Als sie nach Weihnachten ins Pensionat zurückgekehrt war, schrieb sie „un. logische" Briefe, sie sei todunglücklich, werde bald sterben, sie sei selbst schuld. Als die Mutter sie abholte, erschien ihr die Stimme der Tochter fremd, ,wie gemacht“. Sie selbst war ,ohne Gefühl“, nicht froh, nicht traurig. Wieder zu Hause, meinte sie immer, die ganze Stadt interessiere sich dafür, da6 sie im Pensionat nicht ausgehalten habe. Sie wollte nicht mehr ausgehen, aus Furcht, Bekannten zu begegnen. In ihrem Anzug wurde sie ,immer nonnenhafter", alles war ihr 
$\mathrm{zu}$ auffallend. Sie klagte viel, sie sei dumm und zu nichts $\mathrm{zu}$ gebrauchen, und tatsächlich tat sie auch gar nichts. Im Theater saß sie "wie versteinert", als berühre sie nichts. In ihrem Wesen war ,alles Weiche weg“, wenn die Mutter lieb zu ihr war, war sie „wie ein Brett". Kurz vor der Aufnahme in die Klinik hörte sie nachts Stimmen, die sich auf sie bezogen.

In der Klinik bot sie wenig Greifbares. Während der Arzt den Eindruck hatte, durchaus keinen Rapport mit ihr zu bekommen, meinte sie: „Sie verstehen mich ja so gut, ich brauche Ihnen gar nichts zu erzählen." Sie äußerte unklare Selbstvorwürfe, sie habe zu viel gegrübelt, sei ein Ekel, sei ,an allem“ schuld. Sie war voll von Widersprüchen. In einem Satz sagte sie, sie sei gegen die Eltern zu verschlossen gewesen, im nächsten, sie habe ihnen viel zu viel erzählt. Auf die Frage nach ihrer Stimmung meinte sie lachend: „Es ist mir alles Wurst." In ihren Bewegungen war sie außerordentlich sparsam, starr saß sie im Bett, auch bei der Unterhaltung bewegte sie sich kaum. Wiederholt sagte sie, sie habe kein Gefühl mehr, sie käme sich unnatürlich vor. „Ich habe gemeint, ich wäre ein Tier und hätte kein Gefühl mehr." Als sie einmal zugesehen hatte, wie zwei andere Kranke Anfälle hatten, beklagte sie sich nachher darüber, sie habe ohne richtiges Gefühl und ganz mechanisch zugesehen. Sie machte auch in der Tat zu einer der Kranken nach dem Anfall eine lieblose, ironische Bemerkung. -

b) Die nächste Gruppe ist schwer deutbar. Es handelt sich um das Phänomen der Entfremdung der eigenen Gefühle und Akte, wie es sehr oft bei endogen Depressiven, bei Psychasthenischen, aber sicher auch gelegentlich bei psychischen Prozessen vorkommt. Die meisten der mitgeteilten Beobachtungen erlebter Störungen der Liebe und des Mitfühlens gehören hierher, so insbesondere die Österreichs. Auch Schilders schizophrener Student gehört vielleicht hierher. Es ist wahrscheinlich, daß bei Schizophrenen solche Erlebnisse als Vorstadium zum wirklichen Versagen des Gefühlslebens und der Liebe zu anderen vorkommen. Meist wird man hier zweifeln, welcher Typus vorliegt.

Charakteristisch für diese Form ist die Tatsache, daß regelmäßig auch eine Entfremdung der Wahrnehmungswelt dabei beobachtet wird, und daß die Entfremdung sehr häufig das ganze Erleben des Kranken erfaßt hat. Hier sind die Ubergänge zur ausgesprochenen Depersonalisation.

Dieses Entfremdungserlebnis ist phänomenologisch etwas Letztes und läßt sich höchstens theoretisch erklären. Es würde zu weit führen, hier auf die zahIreichen Theorien, von denen keine befriedigt, ausführlich einzugehen ${ }^{1}$ ). Es sei nur daran erinnert, daß vor allem eine sensualistische Theorie einer Gefühlstheorie gegenüber steht, die besonders Österreich vertritt. „Die entscheidende Ursache der Entfremdung der Wahrnehmungswelt in der Psychasthenie liegt darin,

1) Die ganze in- und ausländische Literatur findet sich ausfibrlich referiert bei Österreich und Schilder l. c. 
da $B$ die emotionellen Bestandteile der Wahrnehmungsprozesse eine erhebliche Alteration im Sinne der Hemmung (und zwar der Erschöpfungshemmung) erfahren haben." Österreich kommt auf diese Theorie, weil er seinen Kranken die Klagen über Gefühlskälte gla ubt. In diesen Gefühlsstörungen liegt für ihn auch die Ursache der Depersonalisation. Andere Theorien sind nicht viel mehr als eine Umschreibung, so wenn $\operatorname{Pick}^{1}$ ) von einem „Ausfall des Bekanntheitsgefühls" spricht. Sehr viel weiter scheint mir auch Schilder nicht gekommen zu sein, der gegen Österreich mit Recht einwendet, daß die Tatsache, daß der Ausdruck der Gefühle im Gegensatz zum wirklichen Gefühlsmangel Schizophrener stets vorhanden sei, sehr gegen die Richtigkeit seiner Theorie spreche. Er versucht das Problem mit phänomenologischer Psychologie, insbesondere gestützt auf die Inschauungen von Pfänder und Haas über die unechten Gefülle, anzufassen. Von dem Begriff der Evidenz als der ,Vereinheitlichung aller aktiven Tendenzen" ausgehend, nimmt er auch eine Evidenz der Gefühle an. Die Gefühlsstörung der Depersonalisierten ist für ihn darin gegeben, daß das Individuum keine evidenten, im Einklang mit dem Gefühlshintergrunde stehenden Gefühle vollzieht. Es entsteht dann ausschlieBlich ein nicht aus der Tiefe des Ichs kommendes, ein unechtes Gefühl. Die Unechtheit des Gefühls wird dann zum Gegenstand eines neuerlichen Aktes gemacht. „Die Kranken erkennen die Gefühle deswegen nicht als ihre eigenen an, weil sie in nicht evidenter Weise vollzogen werden. Diese Nichtevidenz wird in einem neuen Akte wahrgenommen". $\mathrm{Zu}$ dieser Theorie ist di 3 Annahme notwendig, daß auch Gefüble in Akten gegenständlich erfaßt werden. Ähnlich wie die Entfremdung der Gefühle ist die Entfremdung aller anderen Akte, also auch der Liebe, zu deuten. In ausgesprochenen Fällen findet sich im ganzen Erleben eine solche Widersprochenheit.

Beobachtungen zu dieser Gruppe sind folgende:

Beobachtung 4. Die 67 jährige Kaufmannsfrau Bertha Hirsch hatte mit 42 Jahren zum erstenmal einen mehrere Monate lang dauernden Verstimmungszustand, ebenso mit 57 und mit 64 Jahren. Stets standen die Klagen großer Entschlußlosigkeit, Arbeitsunfähigkeit, Freudlosigkeit im Vordergrunde, stets glaubte sie, nie mehr gesund zu werden. Mit 67 Jahren trat wieder derselbe Zustand auf der sie in die Klinik führte. Sie klagte, sie sehe alles wie durch einen Schleier, sei auch bei nichts recht dabei: „Wenn ich einen Brief schreiben will, schreibe ich mit dem Kopf, aber nicht mit dem Herzen."

Beobachtung 5. Die 47jährige verwitwete Verkäuferin Pauline Reuter hatte zum erstenmal vor ihrer Verheiratung, mit 30 Jahren, einen Verstimmungszustand mit religiösen Grübeleien und allerlei körperlichen Sensationen. Im Krieg verlor sie nach kurzer, glücklicher Ehe ihren Mann. Nachdem er 18 Monate vermißt war, erfuhr sie seinen Tod. Trotz tiefer Trauer wiederholte sich der

1) Zur Pathologie des Bekanntheitsgefühls. Neurol. Centralbl. 22. 1903. 
frühere Zustand nicht, wohl aber $1 \frac{1}{2} \mathrm{Jahr}$ später, ohne daß ein Grund vorlag. Sie wurde niedergeschlagen, „kein richtiger Mut mehr, immer matt, keine rechte Lust". Sie grübelte viel über ihre Sünden, bediente „nur noch mechanisch", vernachlässigte ihre kleine Wirtschaft. Nach einem Versuch, sich mit Gas zu vergiften, kam sie in die Klinik. Sie war tief depressiv: „daß es am Ende doch nicht von den Nerven, sondern richtig Schlechtigkeit ist". Auf die Frage, wie sie mit Mutter und Schwester stünde, brach sie in Tränen aus: „Ich kann keinen mehr gern haben, das istes ja gerade." Wenn sie vom Geschäft nach Hause in ihr Zimmer gekommen sei, habe dort alles anders ausgesehen, hauptsächlich das Christusbild und die Bilder der Angehörigen; nichts habe ihr mehr etwas gesagt. -

Am ausgeprägtesten pflegen aber diese Klagen über „,Gefühlsleere" ", mangelnde Liebe und mangelnde Tejlnahme an anderen zusammen mit Entfremdung auch der Wahrnehmungswelt bei Psychasthenischen zu sein. Eine Beobachtung, die gerade das Erleben fehlender Liebe und fehlenden Mitfühlens in unendlich lebendiger Schilderung zeigt, sei ausführlicher mitgeteilt. Beachtenswert ist, wie die Kranke geradezu Experimente anstellt, um zu erproben, ob sie noch mitfühlt. Auch die Entfremdung der Wahrnehmungswelt und der eigenen Persönlichkeit dürfte kaum jemals so anschaulich geschildert worden sein.

Beobachtung 6. Die jetzt 38 jährige Lehrerin. Else Pohl, ein kluger und sensitiver Mensch, litt seit frühester Kindheit an Zwangsvorstellungen aller Art auf dem Boden eines ständigen Schuld- und Insuffizienzgefühls. Dieses steigerte sich mit den Jahren so sehr, daß sie in der Form ausgesprochener Erinnerungsfälschungen in ihrer Vergangenheit allerlei Vergehen entdeckte, die sie begangen haben wollte ${ }^{1}$ ). Nach Jahren traten diese Quälereien mehr in den Hintergrund, dagegen entwickelte sich anschließend an eine gynäkologische Operation ein monatelang dauernder Zustand von Entfremdung der Welt und des eigenen Ichs. Sie schreibt darüber:

10. IV. „Sinn- und Gedankenlosigkeiten tu ich jetzt sehr häufig und seh mir ganz verwirrt selber dabei zu. Ihnen kann und darf ich schreiben, wie ich empfinde, denn Sie verstehen mich und sind mir noch nicht fremd geworden wie alles andere um mich her. Vor meinen eigenen Geschwistern, die mich mit treuester Sorge umgeben, $m u B$ ich eine unglaubliche Reizbarkeit verbergen; was sie mir sagèn, klingt mir fremd und unverständlich, und ich merke, daß meine Fragen und Antworten sie verletzen und befremden. Die Menschen, mit denen ich hier zusammen bin, stehen mir ablehnend, geradezu feindlich gegenüber, und meine Finstellung auf sie ist auch dementsprechend. Das bin ganz bestimmt nicht ich selbst, der da mit ihnen zu Tisch sitzt, denn ich konnte mich doch unterhalten, den Gedankengängen anderer folgen und mit Teilnahme zuhören. Hab' ich das getan: einen schauderhaften Roman rückwärts gelesen und heute mit Befriedigung den Anfang als Schluß genossen? Meine eigenen schönen Bücher, die meine Ge-

1) Die Beobachtung wurde ausführlich mitgeteilt diese Zeitschrift 28. 1915. Jas pers bezeichnet in der 2. Auflage seiner Allgemeinen Psychopathologie den Fall als unklar, weil er solche Erinnerungsfälschungen nur bei psychischen Prozessen sah. Daß ein solcher hier nicht vorliegt, zeigt auch die jetzige Mitteilung. 
schwister mir hergeschleppt haben, sehen mich fremd und verständnisios an, ich habe kein Verhältnis mehr zu ihnen. Auch nicht mehr zu anderen feinen und schönen Dingen. Es ist alles in einer großen Leere ertrunken."

26. IV. „Das wird ein rechter I chbrief werden, drum blieb er vielleicht besser ungeschrieben. Aber mir ist so verworren zu Sinn, so angstvoll traumhaft, daß ich nich nach Wirklichkeiten umsehen muß. Wine Aussprache mit Thnen gehört noch dazu. Wie ist fast alles andere mir doch so schattenhaft, so wesenlos und fremd geworden. Am fremdesten bin ich mir selbst. Ich habe mich ganz und gar von mir getrennt, gehorche mir einfach nicht mehr und seh allen Torheiten und Nöten meines Ichs rat- und hilflos zu. End den Leuten sag ich heimlich: seht mich nicht so seltsanı an und geht nicht alle fort, es ist wirklich nicht meine Schuld, daß alles so gekommen jst, mein Ich gehoreht mir nicht mehr, es ist mir fortgekommen, ich weiß selbst nicht wohn, und ihr solltet sehen, wie anders es wäre, hätte ich es noch in meiner Gewalt. Es hat auch alles mitgenommen, was mir lieb und freundlich war. Wie schrecklich ist das. Und nicht wahr, es sieht hübsch aus, im Liegestuhl liegen und ein schönes Buch in der Hand halten. Aber ob auch wohl einer sieht, daß ich dann manchmal neben mir stehe und mich verwirrt betrachte und nicht weiß, was das bedeutet? Mir ist alles so fremd, so fern, unerkennbar; kein Wunder, da mein Ich nicht bei mir ist, dem die Dinge vertraut und bekannt sind. So sind mir Wege, Menschen, Bilder, Töne fremd, weil der kundige Führer und Deuter fehlt. I'm mich her seh' ich nur Unbekanntes, Unerklärliches, Unlösbares."

24. V. ,Ich bin nicht mehr ungeduldig und habe hübsch warten gelernt. Ich bin auch sicher, daß ich einmal alles wiederfinden werde, was mir hier verloren ging, ist's mir doch, als hab' es jemand mit sachter Hand nur in Verwahr genommen, um es mir, früher oder später, wiederzugeben, und dann erst werde ich es schätzen und lieben und den rechten Gebrauch davon machen. Noch aber macht der bloße Versuch, mich mitzufreven, mitzuleiden, ein häßliches Zerrbild aus mir und das endliche Dochnichtkönnen schafft mir leidvolle Qual. Aber es wird alles anders werden."

30. V. „Ärgerlich, nein vielmehr recht traurig bin ich darüber, daß ich gestern nun a uch Ihnen so versunken, so ohnbegreifend gegenübersaß. Ich fühle den Vorgang des Vertrocknens, nein des Versteinerns meiner selbst ja so schmerzhaft deutlich. Ich suche an den sonnigen Plätzchen des Gartens alte Mütterchen auf und la 3 mir ihre meist so freudlose, armselige Geschichte erzählen; ich zieh' ein mitleidiges Cesicht und versuche, etwas zu empfinden: der Versuch mißlingt. Ein Familienvater erzählt mir voll Stolz von seinen sieben wohlgeratenen Kindern, fünf sehr schönen Töchtern und zwei Söhnen, die als Offiziere im Krieg Tüchtiges geleistet haben; êr zeigt mir Briefe und Photographien; ich höre anscheinend voll Teilnahme zu, frage viel nach Kinzelheiten, so daß ich mir fast unbescheiden vorkomme; ich will mich doch mit dem Mann freuen, seine Töchter sind wirklich schön und die beiden ältesten werden demnächst heiraten, alle haben etwas Tüchtiges gelernt, die Jungen sind beide Juristen und mit verhältnismäßig kleinen Mitteln hat der Mann das fertiggebracht. Hier ist wirklich Grund, sich mitzufreuen, und die ganze Tischgesellschaft tut es auch. Nur ich kann es nicht. Bin ich neidisch, verbittert? Nein Lebtag hab' ich mich davor gehiitet, und nun sollte es mir plötzlich angeflogen sein? Es sind ein paar allerliebste Kinderchen hier; seh ich im Garten von weitem eins kommen, so sagt es in mir: Kinder muß man liebhaben, freundlich und zutraulich mit ihnen sein - und sie laufen vor meinem gewaltsam freundlichen Gesicht davon. Warum schreibe ich niemals Glückwunsehoder Beileidsbriefe? Warum mache ich nie einen Krankenbesuch? Warum berührt mich das Schicksal meiner Schulkinder — und es sind wirklich arme Würmer 
dabei - so ganz und gar nicht? Warum arbeite ich nicht in der Armen- oder Waisenpflege, wie fast alle anderen Lehrerinen in der Großstadt tun? Dabei fühle ich, und das ist wohl das Entsetzlichste, wie mir Schicksal, Innen- und Außenleben meiner Geschwister gleichgültig wird. Ias darf und darf nicht sein, und ich muß mir Mühe geben, mich mehr in sie hineinzufühlen. Aber mir ist alles so fern, so fremd, so unbelebt, ich geh in einem unbekannten Land und suche, was ich einmal war. Ich bin mit niemand mehr verwandt, Menschen und Dinge weichen vor mir zuruick und wollen sich nie mehr einfangen lassen. Ich geh ihnen zwar entschlossen nach, oft mit list und unter allerlei Vorwand, und finde doch nichts und werde müd' und trostlos. Drum freu' ich mich so auf den Abend; dann hört das Suchen auf, und man geht zur Ruhe."

31. V. Tch sehe wohl ein, daß diese Verrückung des Verhältnisses zu Menschen und Dingen in mir selber liegt; warum sollte auch alle Welt ein so allgemeines, wenn auch negatives Interesse an mir nehmen, und so ïngstlich aus meinem Willens- und Gefühlskreis entschwinden wollen? Bei den Menschen könnte ich es allenfalls verstehen, aber die kleinen und stillen Dinge? Blumen und Vögel wollen mir nicht mehr ihre Namen sagen, Farbe, Form und Stimmung reden nicht mehr zu mir. Oder nein, ich höre nicht mehr, was sie sagen, ich bin zugemauert, und durch keine Spalte meines Seins dringt herein, was vielleicht doch gerne $\mathrm{zu}$ mir möchte. Denn es gibt doch sicher Abhängigkeiten von mir, die mich so nötig brauchen, wie ich sie. Und nun können wir nicht zusammenkommen. - So werde ich auch weiter tun, als ob ich Schule hielte, Bücher kaufen und tun, als ob ich läse, mir Blumen und Nettigkeiten schenken lassen und tun, als ob ich mich freute, zur Kirche gehen und tun, als ob jch betete, freundliche Worte sprechen und tun, als ob sie echt wären."

2. VIL. „Ob es mir wohl gelingt, etwas Ordnung in meine wirbelnden Gedanken zu bringen? Die Dinge sind mir körperlich so beängstigend nah und innerlich so fern. Manchmal bin ich selbst vernichtet, seinslos, und manchmal lebe ich so stark, daß mir übel davon wird. Oder nein, ich werde gelebt, ,man läßt mich leben, reden, handeln, tanzen wie eine Drahtpuppe. Nicht ein Restchen Selbstbestimmung hat man mir gelassen. Wenn man mich noch in den sinn des Spieles einweihte! So hör' ich nur mein unentrimnbares Stichwort, muls hervor und wieder zurück, in meinen Winkel, und das zerrissene Spiel rauscht mir sinnlos dahin. - Der Tag ist so laut und hell, und ich bin so ratlos. Wenn ich doch nicht mehr mitzuspielen brauchte. Ich spiele Mitliebe und Mitleid, und das sind meine schwersten Rollen. Ich habe ganz und gar kein Talent mehr dazu, und sie gehören doch zum Beruf Menseh. Und Sichmitfreuen wohl auch. Man sagt, es gebe viele Dinge, die man lieben müsse un ihrer selbst willen, und ich weiß das auch noch von früher, - aber die wundervollen Rosen duf meinem Schreibtisch liebe ich durchaus nicht, and die liebe Hand, die sie dahinsetzte, ist mir gleichgültig. Und ein herziges Wort aus Kindernund hab' ich auch frïher liebgehabt und mich daran gefreut -- heute, belohne' ich so etwas und wirke erziehlich, und kann mich nicht einmal mehr selber darum bemitleiden. Wo andere sich freuen und lieben, tu ich es durchaus nicht, und liest mir jemand ein schönes Gedicht ror, etwa Rilkes ,Der Sohn", und hat seine helle Lust und Freude daran, so tu ich nur als ob' jeh seine freude teilte. Wie kann man nur sohönes und Echtes und Wertvolles sehen und empfinden, an Mensehen und Dingen, und sich nicht mit an ihnen freuen? Wie kanu ich nur ein weinendes, schmerzlich weinendes Kind gleichgültig ,betrachten'? Das tu ich recht oft und seh' mir selber dabei zu. Aber ich kamn ja nicht an das Kind heran, obgleich ich sein Händchen halte und ihm Süßes in den Mund stecke. Was soll das Getue? Welche Beziehung habe ich zu dem Kind? Welche Beziehung habe ich überhaupt zu den Menschen und 
Dingen, die mit mir leben? Warum rücken sie mir so nah und verlangen immer! dieses entsetzliche, als $o b^{6}$ ? Sie sind mir ja doch fern und fremd, sie quälen mich mit ihrer Zudringlichkeit, und ich möchte ihnen oft wehetun deshalb. Und warum verlangt sogar Gott dieses betrügerische ,als-ob"? „Ich will dich lieben, meine Stärke", dahinein rette ich mich. Aber Betrug ist es doch, denn ich hab' ja gar kein Verhältnis mehr zu Gott. Es gab eine Zeit, da hatte man mir ein Abhängigkeitsverhältnis aufgebaut, und ich glaubte es einzusehen, nun sind aber ,Gott' und ,ich' $\mathrm{z}$ wei Begriffe, die ich gar nicht mehr in Beziehung zueinander bringen kann. Und mein ,Eigenwert" und ,ich" ${ }^{6}$. Was haben die noch miteinander zu tun? Meine, Seele' und, ich'? Meine Bücher und, ich'? Die Menschen in der Elektrischen und ,ich', bilden wir überhaupt eine Einheit? Da sitzt ein Kind neben dem anderen und ich stehe davor und andere Leute sind noch dabei, und nun hebt ein sonderbares Spiel an. Man sagt mir, das sei Schulehalten, Unterrichten, plan- und sinnvolle Arbeit. Ich höre viele Worte, aber erkenne keine Zusammenhänge. Früher haben solche Zusammenhänge bestanden, das weiß ich. Sie mögen wohl noch da sein, abér ich nehme sie nicht wahr."

5. VII. „Menschen und Dinge stellen Forderungen an mich, die ich nicht erfüllen kann. Sie sagen: Komm, betrachte uns, reih' uns ein, bewerte uns, und ich muß antworten: ich seh' nur Zerfallenes, Einzelnes an euch; ihr gebt mir kein Bild. Warum strebt alles an euch so mißtönig auseinander? Ich habe keinen Wertmesser mehr für euch. Zudem treibt ihr ein boshaftes Spiel mit mir. Warum weicht ihr zurïck, wenn ich wirklich euch zu betrachten komme? Ihr seht doch, daß ich wieder Freundschaft mit euch schließen möchte. Wenn ich euch aber nicht brauchen kann und nicht haben will, dann seid ihr so bedrohlich nah, da $B$ ich in eure zerfallenen, zerfetzten, zerrissenen Fratzen sehen muß, bis mir ekelt. Und ich hatte euch doch einmal so lieb. Das weils ich noch von früher her. Warum seid ihr so leer und hohl, all ihr schönen Bücher da? Oder kann ich euch etwa nicht mehr zum Reden bringen? Aber ihr könnt doch nicht verlangen, daß ich in euch hineinlese. Wozu seid ihr denn da? Es quält mich, daß ihr so stumm und steif als Zierat dasteht, und ich glaube, ich muß euch fortschaffen. Glaubt ihr, ich ließ mir euer tyrannisches , als-ob noch lange gefallen?"

10. VII. „Liegt nicht ein großer Widersinn darin, zu empfinden, wie Lebendiges und Totes gewaltsam über mich hinströmt und zu gleicher Zeit zu sehen, wie unermeßlich fern mir alles gerïckt ist? Es war mir nah, Vieles und Schönes, das weiß ich noch. Wie soll ich's nur ausdrücken: ich bin mitten im Wasser, aber werde nicht naß. Kann man sich das überhaupt vorstellen? - Ich bin augenblicklich sehr rührig und betriebsam und rede viel, aber es bleibt alles beziehungslos, denn auf die seltsam verzerrten Eindrücke, die mir von meiner Umgebung kommen, bin ich in Tat und Rede nicht eingerichtet. Ich will das Fremde totreden, tothandeln, aber es ist unangreifbar; es ist einfach $\mathrm{da}$, und hat mir meine allereigensten Gebiete entrissen."

13. VII. „Meine Schulkinder haben gute Zeit: es regnet nur so Bildchen, und jeden 'Tag ein Märchen oder zwei. Sie leiden förmlich unter der Überernährung und ahnen nicht, die armen Würmer, wozu ich sie gebrauche. Nun, so ein kleines Versuchstierchen im Laboratorium muß sich auch viel gefallen lassen. Dabei will ich nicht einmal Forscher- und Entdeckerfreuden genießen, sondern nur zurückerobern, was mir von Rechts wegen zukommt, das Sich-mitfreuen-Können. Mit ganz fein berechneten Mittelchen such ich manchmal zu unterrichten und wenn dann wohl etwas ganz Feines, Reines und Liebes bei so einem Kind zum Vorschein kommt, stell ich es vor mich hin und will mich an dem kleinen Wertchen 
freuen und natürlich auch das arme Versuchstierchen liebhaben: es geht nicht. Mit ihren kleinen Schmerzen kommen sic noch immer zu mir, ganz zutraulich, und merken nicht, daß es nur Formeln sind, die ich hersage, wenn ich sie tröste, und daß ich nur ,aus Gewohnheit' helfe. Die Traurigen kann ich brauchen; ihr Leid soll mir zeigen, ob ich noch mitleiden kann. Es geht nicht. Aber vielleicht liegt es daran, weil ich das Leid mitgeschaffen habe und es nicht fühle, weil ich im Grunde doch nur mich selber quäle. Aber all das andere Leid, an dem ich nicht verantwortlich bin? Und die Freude, die viele helle Freude um mich her? Ich gehe. hindurch und nichts davon geht in mich ein."

Zu diesen Entfremdungserlebnissen scheinen mir auch die crlebten Störungen der Liebe in einem eigenartigen Fall zu gehören, dessen Mitteilung nun folgt ${ }^{1}$ ). Besonders bemerkenswert ist hier, wie aus dem schmerzlichen Vermissen der Liebe zu den Eltern die Wahnidee herauswächst: du bist am Ende gar nicht ihr Kind. Dennoch ginge es zu weit, die ganze paranoide Episode als ,Erklärungswahnidee" verstehen zu wollen.

Beobachtung 7. Die sehr belastete, bei der Beobachtung 19jährige Studienratstochter Lili Rohmer war ein sehr lebhaftes und vor allem phantasievolles Kind. Wie sie etwa 16 Jahre alt war, begann zum erstenmal eine Zeit großer Betriebsamkeit, erotischer Erlebnisse, großen Glücksgefühls, die bald genau in das Gegenteil umschlug. Sie wurde pessimistisch, dachte immer „nur tot, nur Ruhe und Frieden". Alle Hausarbeit stand wie ein Berg vor ihr, alle ihre Sünden fielen ihr ein, ,alles Glück ging in Scherben“, sie sah alles Elend des Lebens, sie wurde menschenscheu und fühlte sich einsam und unverstanden. Als sie körperlich abnahm, nicht mehr aB und oft ohnmächtig wurde, kam sie in cin Krankenhaus, wo sie gegen jedermann mißtrauisch und ablehnend war, sich ausspioniert und beobachtet glaubte. Sie kam sich unendlich schlecht vor, glaubte, von Sünden so verpestet zu sein, daB sie auch andere vergifte, und machte einen ernstlichen Versuch, sich die Pulsader zu öfnen. Langsam kam wieder Vertrauen zu den Menschen, „ein Stein um den andern" fiel ihr vom Herzen, und ganz schleichend glitt sie in das „Extrem" hinein. Sie war ,wie in eine andere Welt rersetzt", voll „Lebenshunger", den ganzen Tag am Singen, sah nur das Schöne und Gute, war ausgelassen, unermüdlich in Vergnügungen, ging abends heimlich in Bars, hatte Liebeleien, trank — ,nur leben“" war ihr Gedanke. Auf dem Höhepunkt dieser Episode verlobte sie sich unter großen iußeren Schwierigkeiten, ging aber in denselben Tagen, ohne daß sie etwas dabei fand, mit anderen Männern. Nach äußerst ruhelosen Tagen kam sie selbst, wie sie sagte, um sich zu erholen, in die Klinik. Nach wenigen Stunden begann hier eine phantastische Psychose: sié spielte die heilige Gisela, die „Hexe, die eine Heilige war", glaubte im Himmel zu sein, verkannte Arzt und Pflegerinnen, putzte sich phantastisch heraus, richtete sich eine Kapelle ein und war höchst gewalttätig, wenn man sie in ihrem Spiel zu hindern suchte. Nach 10 Tagen in eine Provinzialanstalt gebracht, wurde sie dort mit einem Schlage besonnen und zeigte nichts mehr als eine deutlich gehobene Stimmung. Als sie einen Brief ihres Verlobten erhalten, in dem dieser in groben Worten die Verlobung auflöste und sie als Dirne bezeichnete, setzte wieder eine

1) Eine klinische Epikrise nub hier wegbleiben; mit der Diagnose manischdepressives Irresein ist die Beobachtung sicher nur unzureichend charakterisiert Die erbbiologische Betrachtung im Sinne $K a h n s$ wäre hier sicher fruchtbar. 
fast 14 tägige phantastische Psychose ein, in der sie wieder die heilige Gisela und zwar diesmal auf ihrer Himmelswanderung durch Hölle und Vorhimmel war. Wieder wurde sie ganz plötzlich einsichtig, wieder hatte sie volle Erinnerung an die Erlebnisse. Sie kam dann zurück in die Klinik und gab dort eine viele Stunden dauernde Schilderung ihres ganzen Lebens und ihrer Psychose, und zwar höchst lebendig und anschaulich. Man hatte völligen Kontakt mit ihr, nichts erinnerte an schizophrene Züge. Die Stimmung war anfangs deutlich gehoben, was sich auch in dem etwas auffallenden Anzug ausdrückte, doch wurde sie bald stiller, ausgeglichener, schließlich sehr nachdenklich. Vor allem sprach die Kranke viel von dem Unrecht, das ihr der Verlobte angetan hatte. In diese Tage fiel ein Besuch der Mutter, die sie lange nicht gesehen hatte und der sie sehr enttäuschte. Sie klagte nachher darüber, sie habe die Mutter gar nicht liebhaben können, sie empfinde überhaupt auf einmal nichts mehr für die Ihrigen, es sei ihr gleichgültig, ob sie lebten oder tot seien. Sie äußerte große Angst, wieder krank zu werden, und sprach von einem ,anderen Ich“, das drohe, sie wieder anzufallen. An diesen Tagen schrieb sie folgendes auf:

\section{„Das zweite Wesen.}

Der Himmel ist bewölkt, es wird traurig, düster draußen, und dann auf einmal alles wieder wie fortgewischt! - Erst zittert das Licht, die Helligkeit, die Freude, dann lacht sie ganz offen; denn sie ist sicher dazubleiben! -

Und so ist auch meine Seele.... .

Die letztvergangenen Wochen hindurch lachte das Licht, die Freude! Nur manchmal, fast im Unterbewußtsein ein leises, eigenes Schwingen, das stärker wurde, wenn der Abend kam und es so still ward, und die lange, lange Nacht vor mir lag.

Da war es auch zuerst, das merkwürdige Gefühl! So, daß ich mich immer fragen mußte: ,Wer bist du ?' Und wie um dieses fremde Wesen mit kaltem Verstande zu verjagen, sagte ich wohl vor mich hin: ,Lili Rohmer, die Tochter des Studienrats Heinrich Rohmer......

Dann aber kam das eigene Gefühl nur stärker, ich mußte manchmal recht scharf überlegen, wo ich überhaupt sei. ,Das eigene Gefühl' wurde immer stärker, immer stärker, und mit ihm kam dann oft eine unerklärliche Angst: was bedeutet das denn alles? Dann auch kamen Zeiten, wo es mich vollständig beherrschte. Ich verspürte nichts mehr von ,Menschsein'. Ich wäre am liebsten gewandelt, wie Geister wandeln, immer fort, immer fort, wohin, das war egal. Ich glaube, wenn ich mich nicht mit dem letzten Rest von Kraft dagegen aufgelehnt hätte, das ,zweite Wesen' hätte mich ganz in Bann getan, und wer mich dann fragen wïrde, wer ich sei, dem hätte ich antworten müssen: ,ein Geist oder noch besser eine zuckende Seele: Denn das andere waren nur leere Worte, die mich auslachten!!

- Und gestern sah ich meine Muttor zum erstenmal wieder, zum erstenmal, seit 14 Wochen, seit diesem Tage! Heute, vor 14 Wochen!!! - lch habe mich unendlich auf das Wiedersehen gefrent, unendlich!!! Mutti war ganz die Alte! Mein treues, gutes Muttchen! Doch schon, als sie noch da war, kam es wieder, ,das zweite Gesicht', wie ich es getauft habe. Erst langsam und mit ihm eine entsetzliche Unruhe und Erregung, wie sie noch nie da war. Als sie ging, da war's vollständig da, es wischte alle Freude, alle Liebe weg.

$\mathrm{Ja}$, nun habe ich es endlich! Alle Liebe hat es fortgenommen. Früher ahnte ich schon so etwas, wenn es da war. Alles leere Worte, sagte es zu mir: ,Vater, Mutter... Und gestern hatte ich mich noch so über Fritz gefreut und trotzdem schrie es: la ß doch, du gehörst gar nicht mehr zu ihnen, du gehörst keinem mehr, hörst du? keinem, auber mir!!! Da hat es mir alles genommen! Alles! Auch den 
letzten Rest Gottesglauben! Gott, wer ist Gott!!? Was ist Gott!? Ich will keinen Gott! Tausendmal nein!!! Ich will Ruhe und Frieden! Und nicht ewiges Suchen und Zweifeln nach ihm. Fragen, Fragen, qualvoll, unendlich, auf die mir doch keiner antwortet! Schluß, aufhören mit Gott will ich! Ich will seine Seligkeiten nicht, ich will Ruhe und Frieden! Und die hat der Tod! Tod ist Vollendung! Tod ist Glück!!! Ich fürchte ihn nicht!!! Aber jetzt noch nicht! Jetzt noch nicht!!! Frst muß ich ihn verdient haben! Erst noch eine große, seelenbefreiende Tat; denn meine Seele ist erstickt von dem ,zweiten Wesen'. Ich fühle sie nimmer! Auch kein Gewissen! Alles tot, alles tot, tot!!! Alles hat es mir genommen: Seele, Gewissen, Liebe, Furcht, Gottesglauben! Alles ist fremd geworden, schal, sinnlos!!! Alles ist tot! Nur meine zuckende Seele ringt noch ein kleines! Doch bald wird, es" sie wohl auch getötet haben, - und ich lache darüber! Ich lache über alles! Über Gott, über meine liebsten Angehörigen, denn ich gehöre ja nicht mehr zu ihnen! zu keinem. Ich bin allein mit ihm, dem ,zweiten Wesen' und lache; denn ich fürchte mich nicht mehr, es" hat mich schon zu fest gepackt! -

Es ist sehr klug, dieses ,zweite Wesen', sehr klug! Fs läßt mich sprechen, reden wie immer! Daß sie nur ja nicht merken, daß es da ist. Fis zeigt erst seine Gewalt, wenn wir allein sind. Und sobald jemand kommt, lauert es im Hintergrund, daß es nur ja nicht den Augenblick verpaßt, wieder zu herrschen! - Ich hasse es eigentlich, denn früher war ich glïcklich. Jetzt? alles Frühere hat es mir entfremdet, genommen, sogar die Tränen, kalt, herzlos bleibt alles! -

Und dann wird der furchtbare Augenblick kommen, wo ich es nicht mehr , das zweite Wesen" nenne, sondern wo ,das zweite" Wesen Ich geworden ist. Ich glaube, einmal gab es schon so eine Zeit, damals im Herbst, als ich krank wurde. Da fühlte ich auch kein Herz, keine Seele, keine Liebe mehr! Nur dieses ,zweite Wesen'! Es hat etwas Satanisches, Dämonisches an sich. Ich konnte meine Eltern und andere liebe Menschen leiden sehen, ohne daß es sich in mir rührte oder vielmehr rühren durfte! Nur ganz hat es mich nie besiegt, denn es kamen Stunden, wo jch schrecklich unter dem Fremden litt! -

Als Kind war es auch manchmal da, und nun ist es mit mir gegangen, bis seine Zeit gekommen! Bis ich mich gar nimmer kenne! Bis ich meine Seele begraben muß, die arme, zuckende, liebeleere Seele!!! . . Aber es gibt auch Zeiten, wo es unendlich leicht macht, dieses zweite Wesen; denn alles hat ja aufgehört: Verantwortung, Pflichtgefühl, Gewissen, Liebe!!! Dann sehen meine Augen alles wie in einem Schleier und es hebt mich fast vom Erdboden, daß ich meine, ich fliege.

Und trotzdem hasse ich es, ja ich hasse es, denn es hat mir das Glück meiner Kinderjahre: meine Mutter, mein Liebstes, alles und alles genommen! -

Ynd in diesem Augenblick, wo ich schreibe, fällt es mir ein, ganz klar! Zweimal war es schon ,Tch' geworden! Zweimal!! Finmal vor 14 Wochen, als ich den Gang ging, der im tiefen Rhein enden wollte, und das zweite Mal, als ich den Brief bekam. Da habe ich gesehrieben, was mir förmlich in die Feder diktiert wurde, und jetzt frage ich - , wann kommst du zum drittenmal ?'

Ich ahne, es mag nicht allzu lange währen!! denn gestern abend zum erstenmal wagte es sich hervor, auch wenn einer dabei war! Und das hat mich entsetzt! Daß es schon so stark geworden... Und ich möchte so gerne zurück in jene glückliche Kinderzeit, wo ich glaubte, kindlich glaubte. Wo ich mich des Lebens freute und aller Zukunft! 
Doch ich bin gebunden, jenes, zweite Wesen' hat Gewalt über mich bekommen und die wächst von Tag zu Zag, von Stunde zu Stunde, von Minute zu Minute. Darum graut mir vor der Zukunft. Vor dieser Zukunft, wo das ,7weite Wesen" , I ch' sein wird. - - -

Ich möchte weit, weit wandern in alle schöne Welt und dann auf einer grünen, bunten Sommerwiese liegen und nur in den Himmel gucken. Vielleicht käme mir dann von da oben wieder alle Kinderseligkeit, ein fester, unerschïtterlicher Glaube an einen Vater des Lichts und ein Leuchten der Zuversicht für alle schwarze. Zukunft. Dann würde ich glücklich sein

- Und morgen kommt wieder meine Mutter. -

Und jetzt schleicht es wieder, das ,zweite Wesen', o wie ich es hasse! Diese Angst, diese Unruhe, die mich fortreißen möchte hinaus, mit offenen Armen ins Unglück. Diesmal aber wäre der Rhein wohl tief genug

Es hat keine Dornen die Wasserros',

Sie trägt den Frieden in ihrem Schol.

Bei ihr auf dem feuchten Seesgrund,

Da werden die Herzen alle gesund. ...

O mich packt ein wahnsinniges Grauen vor dem eigenen Ich, das mir so fremd geworden Ich kenne mich nicht mehr, ich entsetzte mich vor meinen Gedanken! Und manchmal schreit's darinnen ganz deutlich: Mörder! Das ist der letzte Verzweiflungsschrei der Seele Das ,zweite Wesen' arbeitet gründlich, wirklich vorzüglich, und alle Schatten der Erinnerung stehen auf und stellen sich hohnlächelnd an seine Seite: verderbenbringend!!! Der schwarze Balken ist wieder da!! Ja, du hast recht, ich werde noch in Zukunft an dich denken, dafür hast du gesorgt. Der Brief ist zerrissen, aber die Worte leben, glühend in meine Seele gebrannt und ich meinte, sie seien verweht!!! $O$ sie schliefen nur, und jetzt, wo alles sonst tot ist, alle liebe tot, da trauen sie sich wieder hervor, denn sie sind so grausam und schwarz wie das ,zweite Wesen'; und schreien -- schreien gellend, voller Hohn, voller Verachtung! O, wie sie sich weiden an meinen Schmerzen Und nirgends Rettung?!!! ...

Der schwarze Balken hat sich auf mein Herz gelegt und ich kann ihn nicht heben, denn Ich bin tot, es lebt nur das ,zweite Wesen', es ist Ich geworden!" -

Nach wenigen weiteren Tagen wurde sie nachts erregt, sah das höhnische Gesicht des früheren Verlobten zum Fenster hereinschauen, sah Stellen jenes Briefes in feuriger Schrift an der Wand. Sie sagte andern Tags, sie habe den unsinnigen Gedanken, sie sei gar nicht die Tochter des Studienrats Rohmer. Die Frau, die da gewesen sei, sei nicht ihre Mutter. Das könnten nicht ihre Eltern sein, denn sie empfinde ja gar nichts mehr für sie. Sie sei ,irgend jemand“. Die Stimmung schwankte zwischen Lachen und Weinen. Am anderen Tag bestritt sie, da 3 das eine Klinik sei, das sei ein Gefängnis. Alles bekam Bedeutung und Beziehung, andere Kranke waren Detektive, ein beurjaubter Arzt war ,heimlich weggeholt". Alle, die es gut mit ihr meinten, wurden ermordet, ein von ihrem Verlobten angezetteltes Komplott war im Gang. Bald ging auch die äußere Ruhe verloren, sie hörte drohende Stimmen, sah Gesichter und Gestalten, gegen die sie in immer mehr zumehmender Erregung anging. Die Ärzte waren nicht mehr die Ärzte, man bediente sich nur ihrer Masken; jahrhundertelang lag ihre Zeit in der Klinik, an die sie sich genau erinnerte, zurück. Nach wenigen Tagen war sie morgens ganz ruhig, sie sagte zur Nachtwache, sie freue sich, daß der ,böse 
Traum" vorüber sei; doch bald darauf war sie wieder mitten darin in ihrem wahnhaften Erleben, allerdings nur für Stunden: nach dem Mittagsschlaf erwachte sie orientiert, nur die Idee, nicht die Tochter des Studienrats Rohmer zu sein, stellte sie noch bis zum anderen Morgen in Frage. So hatte genaue Erinnerungen und erzählte bis ins einzelste ihre Erlebnisse. Sie war völlig natürlich und äußerte große Sorge, das käme immer wieder. Anfangs meinte sie, das stimme vielleicht doch, daß sie ihre Eltern nicht mehr so liebhabe. Nach deren Besuch war sie aber ganz beglückt, daß das nicht so sei. Sie wurde nach Hause entlassen, wo es aber nicht recht ging. Nach zwei Monaten kam sie tief deprimiert selbst schutzsuchend in die Klinik. Ihre Klagen waren nur, $\mathrm{da} \beta$ das Leben unendlich schwer auf $\mathrm{ihr}$ liege, so da $B$ sie sich nicht $z u$ helfen wisse. Der Vater holte sie andern Tags ab und brachte sie aus pekuniären Gründen in eine andere Anstalt.

c) Es wäre nun noch zu untersuchen, ob es Formen gibt, die einen scheinbaren Defekt des Mitfühlens und der Liebefähigkeit zeigen in der Weise, daß es infolge Versunkenheit in die eigenen Gefühle zu einer fühlenden Aufnahme fremder Erlebnisse gar nicht kommt. Wie wir sahen, hatte Scheler diese „Fühllosigkeit“" als häufige Erscheinung bei Melancholischen dem wirklichen Fehlen des Mitfühlens gegenübergestellt. Die Ausdehnung dieser Möglichkeit auf die Liebe ist sicher gestattet. Wenn auch dieses Verstehen nicht als eine Bedingung der Liebe angesehen werden darf, wird sie doch fraglos unter dem allzu starken Mit-sich-selbst-Beschäftigtsein leiden können. Sicherlich sind diese Störungen von Liebe und Mitfühlen häufig, doch liegt es in ihrer Natur, daß sie als solche kaum erlebt werden, höchstens vorübergehend oder zurückschauend wird der Kranke seine egozentrische Einstellung bemerken. Sobald dies der Fall ist, hat er diese Einstellung schon durchbrochen. Immerhin kann auch dieses Sichbesinnen so beschattet sein von dem eigenen Leid, daß Liebe und Mitfühlen als schwach und unecht konstatiert werden.

Die zwei nun folgenden Beobachtungen gehören vielleicht hierher, doch scheinen sie nicht ganz rein zu sein, da Entfremdungserlebnisse vielleicht eine Rolle spielen.

Beobachtung 8. Die 64 jährige, aus gebildeter Familie stammende, ledige Christine Müller litt seit Monaten unter allerlei körperlichen Sensationen und hypochondrischen Selbstbeobachtungen, die sich nach einer Grippe steigerten. Sie klagte über Nachlassen ihres Frinnerungsvermögens, über Denkunfähigkeit, über die Unmöglichkeit, sich ihre Schwester vorzustellen. Alles um sie her sei leer geworden, sie könne auch keine Sehnsucht mehr empfinden, weil alles wie gelähmt sei. Der Zustand verschlimmerte sich, sie klagte, nicht mehr erkennen, vorgesprochene Worte nicht mehr nachsagen zu können, auch daß sie keine Vorstellungen mehr habe, keine Interessen, kein Gehirn. Die Welt sei nicht verändert, aber sie selbst. Sie könne nicht mehr sehen, sprechen, nicht mehr lieben, nicht mehr fröhlich sein. Alles sei ,so steif wie Holz". Mit anderen könne sie auch nicht mehr fühlen; sie könne etwa einer Schwerkranken nicht mehr helfen, den n sie müsse immer nur an sich denken.

Beobachtung 9. Die 33jährige Kaufmannsfrau Maria Zeiger hatte mit 28. Jahren zum erstenmal eine Periode von Zwangsdenken, die et wa ein Jahr dauerte. 
Sie hatte Angst, sie könne ihren Kindern ein Leid antun, fürchtete überall Gift und hatte daneben ihr selbst lächerliche Ideen: sie sei eine Schwalbe, ein Blatt, der Kaiser. Sie verlor diese Dinge wieder völlig, doch kamen sie während einer Schwangerschaft nach etwa 5 Jahren in verstärktem Maße wieder. Wieder standen Beschädigungsideen im Vordergrunde. Da sie von nichts anderem mehr redete, kam sie kurz nach der inzwischen erfolgten Niederkunft in die Klinik. Sie klagte, sie könne nicht mehr denken, sich nichts mehr vorstellen, und äußerte unzïhlige merkwürdige Ideen, von denen die folgende Niederschrift einen Begriff gibt:

„Wenn ich das Wasser über mir von der Toilette rauschen höre, denke ich. jetzt wird meine Hildegard durch die Röhre gespült. Wenn über mir die Tür aufgeht, denke ich, das Herz von meinem Kind wird aufgemacht. Wenn abends das Licht angebrannt wird, denke ich, wie das erste elektrische Licht in Köln gebrannt hat, hätte das Kind vom Blitz getötet werden müssen, solche Arten habe ich unzählige. Ich sehe i m Geist auf dem Nachttisch einen Brief, die Anrede davon und denke, wie die Anrede geschrieben ist, hätte das Kind sterben müssen, unzählige dieser Art. Ich will immer durchs Zinmer gehen und fragen, ist das nicht eine schöne Blume, ein schöner Tisch usw. Gestern habe ich das Kind umgedreht und habe die inneren Organe außen gesehen. Alle Krankheiten und alles Böse wünsche ich meinen Kindern, nicht wünschen, sondern ich habe nur die Gedanken. Die kleine Gisela lag bei mir im Bett diese Woche, da kam ein Auto, ich sagte: ,horch' zu dem Kind und gleich dachte ioh, da kommit der liebe Gott. Alle Naturerscheinungen, alle Städte und Flüsse, was mir plötzlich einfällt, bin ich oder andere Menschen. Oft denke ich, alle Gegenstände sind die Augen ron uns. Blumen, wenn ich welche sehe, sind Grabesblumen von meinen Kindern, oder Glockenläuten sind Grabesglocken von den Kindern. Stehe ich morgens auf und sehe die Blumen im Badezimmer stehen, denke ich, gleich kommen die Grabesblumen in dein Zimmer. Denke ich an meine Bekannten, so denke ich, die kochen jetzt Totenköpfe, oder irgendein Teil von meinen Kindern. Esse ich ein Stückchen Schokolade von Wiese, so denke ich, ich bin die Schokolade oder lie Firma, die auf der Schokolade steht. So ist es mit allem Essen. Gestern dachte ich, du hättest doch die Hildegard auch Blumentopf oder Tisch oder Stuhl oder Reissuppe usw. nennen können, oder ihr einen Jungennamen geben können."

Auch hier bestanden dauernd Klagen, sie könne ihre Angehörigen nicht mehr liebhaben, alles sei so kalt: „Es ist, als ob mein Innerstes zu einer Salzsäule erstarrt wäre. - Ich meine immer, wenn ich meinen Kindern einen $\mathrm{KuB}$ gebe, das wäre alles nur etwas Erzwungenes." Wochenlang war sie gänzlich erfüllt von diesen Quälereien und sie zeigte auch objektiv gegen ihr Kind, das sie selbst stillte, wenig Interesse. So wollte sie das Kind absetzen. nur damit sie stärkere Beruhigungsmittel bekäme. Immerhin wurde gelegentlich, namentlich wenn man das Kind bewunderte, beobachtet, daß ein Strahl richtiger Mutterliebe über ihr Gesicht ging. Nach etwa achtmonatiger Krankheitsdauer verlor sich der Zustand fast über Nacht.

d) Während in allen bisherigen Fällen Mitfühlen sowohl in der Form von Mitleid wie von Mitfreude als vermindert erlebt wurden, sei nun zuletzt eine Beobachtung mitgeteilt, bei der das Mitleid gesteigert, die Mitfreude vermindert ist, und die Liebesbeziehungen ungestört gebljeben sind. Und zwar liegt auch hier eine Veränderung der Bedingung des Mitfühlens, eine Änderung des Verstehens, vor, und zwar 
in der oben skizzierten Weise, daß infolge des eigenen Leidens mehr Verständnis für das Leiden des Nächsten besteht. Es ist dies dasselbe Verhalten wie bei jenem Philologen Österreichs, der schreibt: ,,Meine natürliche Sensibilität macht mich sehr geeignet, fremdes Leid mitzufühlen." Die Mitfreude liegt entsprechend dem Stimmungsgrundzustand danieder. Gewiß wäre, etwa in hypomanischen Zuständen, das umgekehrte Verhalten denkbar, doch wird es kaum als Veränderung erlebt werden.

Beobachtung 10. Die 20 jährige Zeichenlehrerin Martha Schütter war stets äußerst gewissenhaft und ängstlich und neigte zum Trübsinn. Schon seit Monaten hatte sie gelegentlich geweint und gesagt, sie werde nichts im Beruf leisten, und ihre Ausbildung werde umsonst sein. In der letzten Zeit vor der Aufnahme in die Klinik machte sie sich Sorge, sie koste den Eltern zu viel. In einem Pensionat, in dem sie angestellt wurde, versagte sie, sie hatte Angst vor der großen Klasse; alles war ihr grenzenlos zuwider, an nichts hatte sie mehr Interesse, sie verstand nicht, wie jemand froh sein könne. In einer tiefen Depression kam sie in die Klinik, wo sie tagelang vor sich hin weinte. Sie klagte, die Gedanken rasten durch den Kopf; sie aufzuschreiben, empfand sie als Erleichterung und Erholung. Die Notizen sind voll Grübeleien über ihre Schwäche und Mutlosigkeit, die Schlechtigkeit der Welt im Gegensatz zu früheren Zeiten und voll Sehnsucht, aus dieșer Welt in eine ideale Welt zu fliehen. Der Zustand verlief in Schwankungen. Einnal klagte sie in einem Brief: „Wenn wir im Tagesraum zusammen sind, fühle ich wieder so recht meine Unfähigkeit, zur Unterhaltung beizutragen (selbst in den Tagen, wo es mir gut' geht), ich komme mir unnütz vor, sehne mich nach Einsamkeit und da überkommt mich erst recht ein Gefühl von Unzufriedenheit. Dann suche ich mir die Frage: Warum bist du nun so? Weshalb kannst du nicht mittun, dich wenigstens mitfreuen?" zu beantworten." In einem anderen: „Das fesselndste Buch kann mich jetzt nicht ablenken, auch nicht in den ,guten'Tagen; ich lebe die Sache wohl mit, aber nicht in den vorkonmenden Personen, sondern als kranker Zuschauer, der die Menschen des Buches um ihre Lebensfreude, ihr Selbstbewußtsein, ihre Tatkraft, ihren gesunden Idealismus beneidet, deren Schlechtigkeit ihm im Innern wehtut. Vom Schicksal heimgesuchte Menschen bemitleidet man, man kann ihren Schmerz verstehen; man möchte trösten, helfen und wird sich dann erst wieder bewußt, daß die Krankheit einen hingerissen hat, das Geschick der betreffenden Personen so unnatürlich tragisch zu nehmen. " Langsam besserte sich ihr Befinden. Nach einem halben Jahr wurde sie entlassen. Sie war nicht mehr depressiv, aber das zarte, scheue und weiche Wesen, das sie immer gewesen war. Zur Aufnahme des Berufes konnte sie sich nicht entschließen.

Fassen wir die hier beschriebenen psychologischen Möglichkeiten der erlebten Störungen von Liebe und Mitfühlen noch einmal zusammen, so waren es folgende Typen, die wir fanden:

1. Es kann eine tatsächliche Herabsetzung dieser Phänomene bestehen. Und zwar

a) habituell,

b) entwicklungsmäßig,

c) prozeßmäßig. 
2. Es kann vorkommen, daß ein Entfremden des gesamten Erlebens dem Erlebenden auch diese Akte entfremdet.

3. Es kann am fehlenden Verstehen liegen in der Weise, daß infolge Versenktseins in die eigenen Gefühle es zu einer fühlenden und liebenden Aufnahme des anderen nicht kommt.

4. Endlich kann bei depressivem Grundzustand infolge vermehrten eigenen Leidens Mitleid gesteigert, Mitfreude vermindert sein. -

Auf klinische Fragen einzugehen, ist hier nicht der Ort. Es sei nur darauf hingewiesen, daß namentlich das Erlebnis der Entfremdung sowohl bei Psychopathen wie bei motivlos Depressiven wie bei Schizophrenen vorkommen kann. Man muß ganz ohne klinische Vorurteile untersuchen. Eine allzu frühe klinische Etikette ist ohnedies allzu oft der Tod psychopathologischen Verstehens. 